\title{
RETENÇÃO E DISPONIBILIDADE DE ÁGUA EM DOIS SOLOS DA AMAZÔNIA CENTRAL
}

ELIAS DE FREITAS JUNIOR

Orientador: DR. KLAUS REICHARDT

Dissertação apresentada à Escola Superior de Agricultura "Luiz de Queiroz", da Universidade de São Paulo, para obtenção do título de Mestre em Energia Nuclear na Agricultura.

PIRACICABA

Estado de São Paulo - Brasil

Junho, 1981 
A Maria Cristina, esposa;

à Maria Paula e Maria Cláudia, filhas;

ao Edélcio e à Raquel, irmãos,

$$
\text { OFERE\&O }
$$

Aos meus pais,

Elias e Dirce,

DE D I C O 


\section{AGRADECIMENTOS}

- Ao Dr. Klaus Reichardt, a orientação;

- ao Dr. Paulo Leonel Libardi a inestimável colaboração na elaboração e revisão deste trabalho;

- aos colegas Antonio Carzos Saraiva da Costa João Eduardo Pilotto Jośé Carlos de Araújo Silva Marcelo Calvache Ulzoa Paula Pinheiro Padovese Reynaldo Luiz Victória Segundo Urquiaga Caballero Sérgio Oliveira Moraes, o sempre presente apoio;

- ao Instituto Nacional de Pesquisas da Amazônia (INPA), a oportunidade oferecida;

- ao Centro de Energia Nuclear na Agricultura (CENA), as facilidades oferecidas;

- à Comissão Nacional de Energia Nuclear, a bolsa concedida;

- à Escola Superior de Agricultura "Luiz de Queiroz" (ESALR), os ensinamentos. 
$-i i i-$

AGRADECIMENTO ESPECIAL

Dr. Warwick Estevam Kerr

Dr. Klaus Reichardt

Dr. Paulo Leonel Libardi 


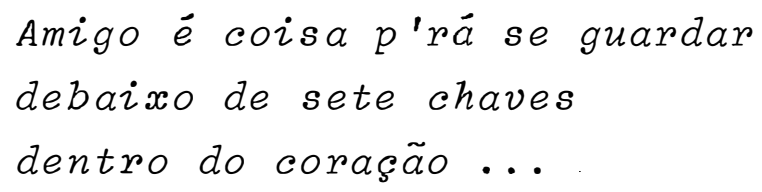

Amigo é coisa p'rá se guardar

no lado esquerdo do peito

mesmo que o tempo e a distância digam não...

Pois seja o que vier, venha o que vier, qualquer dia, amigo, eu volto

a te encontrar, qualquer dia, amigo, a gente vai se encontrar

(Nascimento e Brandt)

Ao amigo

Rui Corbani dos Santos Caio, que não pôde estar aqui hoje, a nossa saudade ... 
IN D I C E

Pāgina

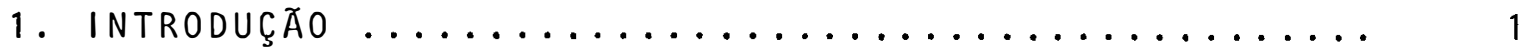

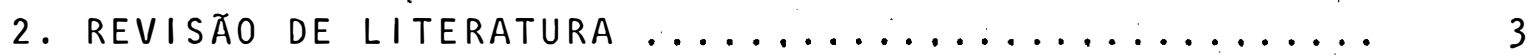

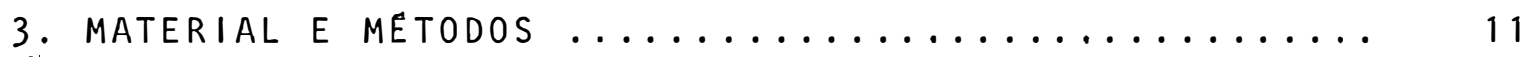

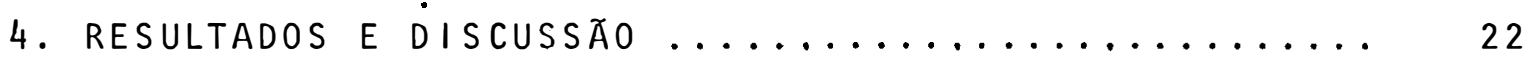

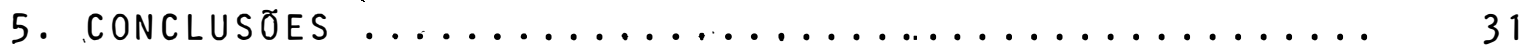

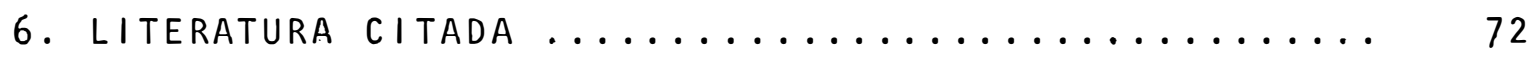


LISTA DE TABELAS

Tabela

Păgina

1 - Densidade global $\left(\mathrm{g} \cdot \mathrm{cm}^{-3}\right)$ das camadas 0-20, 20-40 e 40-60 cm de profundidade de todas as

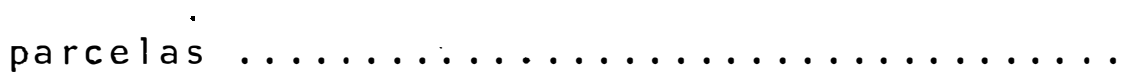

2 - Teor de matēria orgânica (\%) das camadas $0-20,20-40$ e 40-60 cm de profundidade de to

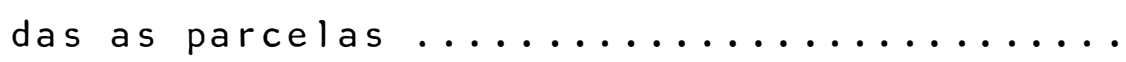

3 - Valores das porcentagens de areia, limo e argi la e classe textural de todas as parcelas, pa ra a camada $0-20 \mathrm{~cm}$ de profundidade .......

4 - Valores das porcentagens de areia, limo e a gila e classe textural de todas as parcelas, para a camada 20-40 cm de profundidade ....

5 - Valores das porcentagens de areia, limo e a gila e classe textural de todas as parcelas, para a camada 40-60 cm de profundidade ....

6 - Valores de umidade volumétrica correspondentes às tensões 0,$0025 ; 0,03 ; 0,06 ; 0,33 ; 1$ e 15 atm de todas as parcelas, para a camada

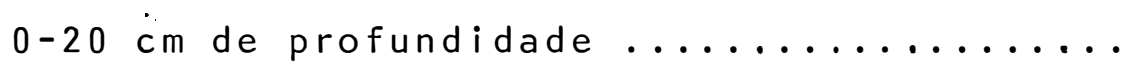


7 - Valores de umidade volumétrica correspondentes às tensões 0,$0025 ; 0,03 ; 0,06 ; 0,33 ; 1$ e 15 atm de todas as parcelas, para a camada

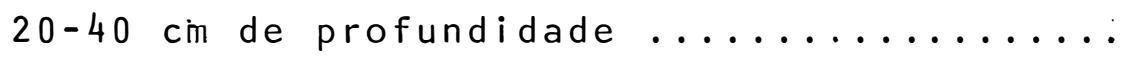

8 - Valores de umidade volumétrica correspondentes às t.ensões 0,$0025 ; 0,03 ; 0,06 ; 0,33 ; 1$ e 15 atm de todas as parcelas, para a camada

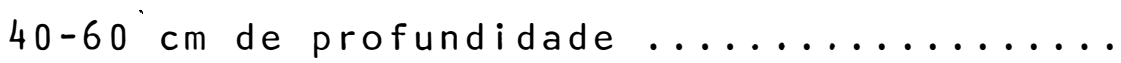

9 - Correlações lineares entre umidade volumétri ca cor espondente à tensão $1 / 3$ atm e componentes do tamanho de partículas $(A=$ argila; $A+L=\operatorname{argila}+1 \mathrm{imo}$ e $A+L+A F=\operatorname{argila}+1 \mathrm{imo}$ + areia fina), para as camadas 0-20, 20-40 e 40-60 cm de profundidade e para todo o perfil $(0-60 \mathrm{~cm})$ da àrea experimental .......

10 - Correlações lineares entre umidade volumétr ca correspondente à tensão 15 atm e componentes de tamanho. de particulas ( $A=$ argila; $A+L=\operatorname{argila}+1 i m o, A+L+A F=\operatorname{argila}+1 i m o+$ areia fina), para as camadas $0-20,20-40$ e 40-60 cm de profundidade e para todo o perfil $(0-60 \mathrm{~cm})$ da ärea experimental ....... 
11 - Valores de capacidade de àgua disponível (mm) das camadas 0-20, 20-40 e 40-60 cm de profundidade de todas as parcelas, considerando $1 / 3$ e 15 atm como limites superiore inferior, res

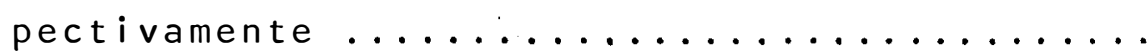

12 - Valores de capacidade de àgua disponível (mm) das camadas 0-20, 20-40 e 40-60 cm de profundidade de todas as parcelas, considerando 0,06 e 15 atm como limites superior e inferior,res

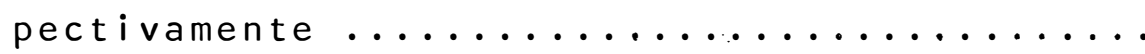

13 - Correlações lineares entr.e ägua disponível $(1 / 3$ e 15 atm como limites) e componentes do tamanho de partículas $(A=\operatorname{argila;} A+L=\arg \underline{i}$ $1 a+1 i m o ; A+L+A F=a r g i l a+l i m o+a r e i a f i-$ na) para as camadas 0-20, 20-40 e 40-60 cm de

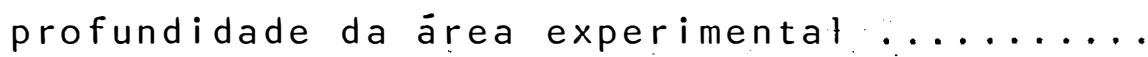

14 - Correlações lineares entre agua disponível (0,06 e 15 atm como 1 imites) e componentes do tamanho de particulas $(A=\operatorname{argila} ; A+L=\arg \underline{i}$ $l a+l i m o ; A+L+A F=\operatorname{argila}+1 i m o+\operatorname{areiafi-}$ na) para as camadas 0-20, 20-40 e 40-69. cm de profundidade da área experimental .......... 
15 - Valores de umidade adimensional correspondentes às tensões 0,$0025 ; 0,03 ; 0,06 ; 0,33 ; 1$ e 15 atm, de todas as parcelas, para a camada $0-20 \mathrm{~cm}$ de profundidade $\ldots \ldots \ldots \ldots \ldots \ldots$

16 - Valores de umidade adimensional correspondentes às t.ensões 0,$0025 ; 0,03 ; 0,06 ; 0,33 ; 1$ e 15 atm, de todas as parcelas, para a camada $20-40 \mathrm{~cm}$ de profundidade .............. 48

17 - Valores de umidade adimensional correspondentes às tensões 0,$0025 ; 0,03 ; 0,06 ; 0,33 ; 1$ e 15 atm, de todas as parcelas, para a camada

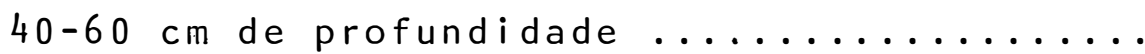

18 - Valores médios de umidade volumétrica adimensionalizada ( $\Omega$ ) e fração de água liberáda ( $\lambda$ ) para cada classe textural da camada 0-20 cm. 
LISTA DE FIGURAS

Figura

Pägina

1 - Diagrama da ārea experimental de dimensões $300 \mathrm{~m} \times 400 \mathrm{~m}$, dividida em 4 blocos e 32 par-

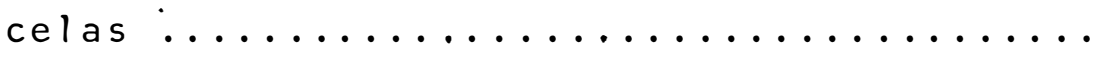

2 - Sistema de câmaras de pressão de Richards (adaptą̧ão do Catālogo da Soil Moisture Equipment Co.) $\ldots \ldots \ldots \ldots \ldots \ldots \ldots \ldots \ldots \ldots \ldots$

3 - Esquema da mesa de tensão utilizada para de terminação das tensões de 0,0025 e 0,03 atm

4 - Campo de umidade em porcento em volume, cor respondente à tensão 0,06 atm, para a cama-

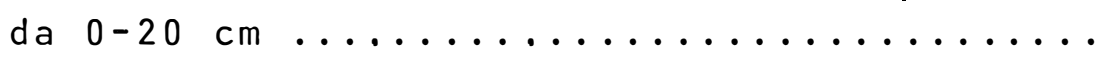

5 - Campo de umidade em porcento em volume, cor respondente à tensão $1 / 3$ atm, para a camada

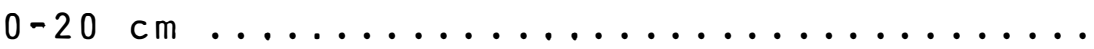

6 - Campo de umidade em porcento em volume, cor respondente à tensão 15 atm, para a camada

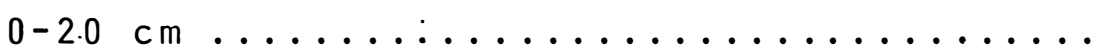

7 - Campo de umidade em porcento em volume, cor respóndente à tensão 0,06 atm, para a cama-

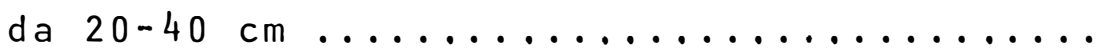


8 - Campo de umidade em porcento em volume, correspondente à tensão $1 / 3$ atm, para a camada

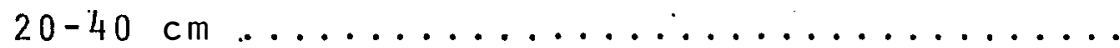

9 - Campo de umidade em porcento em volume, correspondente à tensão 15 atm, para a. camada

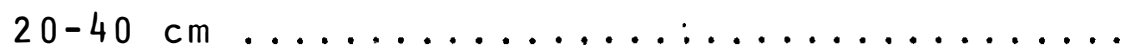

10 - Campo de umidade em porcento em volume, correspondente à tensão 0,06 atm, para a camada

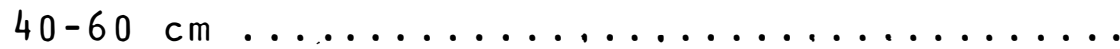

11 - Campo de umidade em porcento em volume, correspondente à tensão $1 / 3$ atm, para a camada

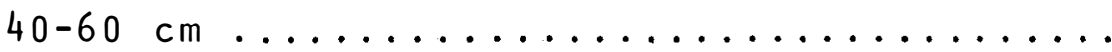

12 - Campo de umidade em porcento em volume, correspondente à tensão 15 atm, para a camada

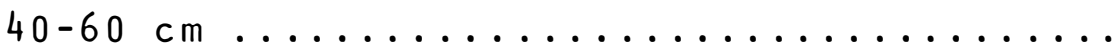

13 - Campo de āgua disponível em mm de ăgua, considerando 0,06 e 15 atm como limites, para a camada $0-20 \mathrm{~cm} \ldots \ldots \ldots \ldots \ldots \ldots \ldots \ldots$

14 - Campo de àgua disponível em mm de àgua, considerando $1 / 3$ e 15 atm como limites, para a camada $0-20 \mathrm{~cm} \ldots \ldots \ldots \ldots \ldots \ldots \ldots$ 
15 - Campo de ägua disponível em mm de āgua, considerando 0,06 e 15 atm como limites, para a camada $20-40 \mathrm{~cm} \ldots \ldots \ldots \ldots \ldots \ldots \ldots \ldots \ldots \ldots \ldots \ldots \ldots$

16 - Campo de āgua disponível em mm de āgua, considerando $1 / 3$ e 15 atm como limites, para a camada $20-40 \mathrm{~cm} \ldots \ldots \ldots \ldots \ldots \ldots \ldots \ldots \ldots \ldots \ldots \ldots \ldots \ldots$

17 - Campo de àgua disponível em mm de āgua, considerando 0,06 e 15 atm como limites, para a

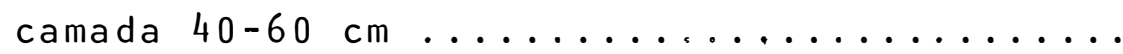

18 - Campo de āgua disponível em mm de āgua, considerando $1 / 3$ e 15 atm como limites, para a camada $40-60 \mathrm{~cm} \ldots \ldots \ldots \ldots \ldots \ldots \ldots \ldots \ldots \ldots \ldots \ldots$

19 - Curvas características médias de retenção de ägua, correspondente às classes texturais: muito argilosa (ma), argilosa (a), arenoargilosa (aa) e areno-barrento (ab), da cama da $0-20 \mathrm{~cm}$ de profundidade $\ldots \ldots \ldots \ldots \ldots$

20 - Curvas características médias de retenção de ägua, correspondente às classes texturais: muito argilosa (ma), argilosa (a), barrento (b), areno-argilosa (aa) e areno barrento(ab), 
da camada 20-40 cm de profundidade ........

21 - Curvas características média's de retenção de água correspondente às classes texturais: muito argilosa (ma), argilosa (a), areno-argilosa (aa) e areno-barrento (ab), da camada

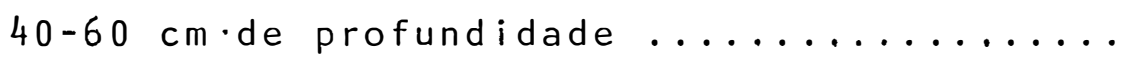




\title{
RETENÇAO E DISPONIBILIDADE DE AGGUA EM DOIS SOLOS DA \\ AMAZŌNIA CENTRAL
}

\author{
Elias de Freitas Junior
}

\begin{abstract}
Klaus Reichardt
Orientador -
\end{abstract}

\section{RE SUMO}

Este trabalho trata da caracterização de aspeç tọs físico-hídricos de dois solos da Estação Experimental de Silvicultura Tropical do CNPq/INPA, no município de Manaus.

\begin{abstract}
A área estudada possui $120000 \mathrm{~m}^{2}$, e nela ocorrem diferentes solos: Latossol Amarelo e Podzólico Vermelho Amarelo. Ela foi dividida em 32 parcelas de $50-75 \mathrm{~m}$ e, no ponto central de cada parcela, foram abertas trincheiras, de onde foi coletado material nas profundidades 0-20, 20-40 e 40$60 \mathrm{~cm}$. Com estas amostras foram feitas análises de retenção de água e granulumetria. A partir dos resultados destas, quantificou-se a água disponível para as 32 parcelas. Neste desenvolvimento experimental, foram utilizados como limites superiores para seu cálculo as tensões 0,06 e 0,33 atm. Pos teriormente, procurou-se relacionar estes valores com as clas
\end{abstract}


ses texturais encontradas nos solos estudados.

São apresentados "campos de umidade" e "campos de disponibilidade" de água para as diversas profundidades, na forma de linhas de iso-umidade e iso-disponibilidade e equações de regressão que permitem calcular a umidade do solo nas tensões 0,33 e 15 atm, a partir do seu teor de argila.

Também são apresentados dados de umidade volumétrica adimensionalizados, que permitem visualizar a liberação de água pelas parcelas. 


\title{
WATER RETENTION AND ITS AVAILABILITY IN TWO SOILS OF \\ "AMAZŌNIA CENTRAL"
}

\author{
Elias de Freitas Junior
}

Klaus Reichardt

- Adviser -

\section{SUMMARY}

The physical characterization of two soils from "Estação Experimental de Silvicultura Tropical CNPq/INPA, Manaus, AM", is presented in this paper.

The area studied has $120000 \mathrm{~m}^{2}$ in which the soils Latossol Amarelo and Podzólico Vermelho Amarelo are found, and was divided in 32 plots of $50 \times 75 \mathrm{~m}$. In the center of each plot, samples were colected at the depths of 0-20, 20-40 and 40-60 cm, for soil-water retention and mechanical analysis. The available water was quantified for all 32 plots.

\section{The available water capacity concept has been} very discussed mainly for the soil water tension upper limit utilized for its determination. In this work two upper limits $(0,06$ and $1 / 3 \mathrm{~atm})$ were utilized. These values were correlated with the textural classes found in the area. Also presented are "water content and water availability fields" through iso-moisture and iso-availability lines, and dimensionless soil water content. 


\section{INTRODUÇAO}

A Amazônia Brasileira ocupa, aproximadamente, $5.10^{6} \mathrm{~km}^{2}$, dos quais $3.10^{6} \mathrm{~km}^{2}$ são ocupados pelas florestas de terra firme. Essas ăreas de terra firme eștão sendo o objeti vo principal dos projetos de "desenvolvimento agropecuário".Es ses projetos são instalados nessas áreas sem que se tenha um conhecimento sólido das alteraçóes sofridas por esse ecossiste ma quando a vegetação primária é substituída por outro tipo de cobertura vegetal.

Também sobre as características físicas e hí dricas dos solos da Amazônia, praticamente nada é conhecido, de tal forma que um estudo desta natureza, para solos desta re gião, além de fornecer informações básicas nécessárias para compreender a dinámica da água e dos nutrientes para à condução de experimentos futuros, caracteriza mais uma área da região amazônica. Esta caracterização foi feita atendendo às dificuldades na condução de experimentos na região. Devido a isto, as amostras de solo foram coletadas na região e transpor 
tadas, na forma de terra fina seca ao ar, para Piracicaba, SP, onde foram analisadas. Procurou-se correlacionar a umidade e a capacidade de água disponível dos solos com suas classes texturais. Estas medidas, apesar de suas limitações, permit rão uma comparação destes solos com outros bem estudados e conhecidos, de outras regiões do país.

A retenção de água pelo solo e sua disponibili dade para as plantas são características que variam largamente em função de uma série de fatores do sqlo, entre eles, a textü ra, estrutura, densidade global, porosidade, natureza da matriz e teor de matéria orgânica. "Embora muitos trabalhos estejam sendo realizados no sentido de melhor compreender estes fatores, em se tratando de solos da região amazônica, como já foi dito, poucas são as informaçõés disponíveis. 


\section{REVISAOO DE LITERATURA}

A agua no solo encontra-se num determinado estado de energia, definido pelo que chamamos potencial total da água no solo, que é a somatória de diversos componentes conhecidos como gravitacional, osmótico, de pressão e matricial. Os componentes de pressão, gravitacional e osmótico podem ser descritos analiticamente, o que não acontece com o componente matricial, que só pode ser determinado experimentalmente (REICHARDT, 1975). Em estudos de comportamento do solo quanto à retenção de água em condições de laboratório, o potencial matricial é o que apresenta efetivo interesse, visto que o potencial osmótico só é considerável em solos salinos em contato com paredes semipermeáveis, o de pressão só aparece em solos saturados e o gravitacional, na maioria dos casos é negligível. 
uma dada umidade pode ser determinado através de câmaras de pressão de Richards, funis de placa porosa ou mesa de tensão, dependendo de sua magnitude. Para valores baixos lteor de água na amostra entre a saturaçao e tensões de $30 \mathrm{~cm}$ de coluna de água), utilizase a mesa de tensão (JAMISON e REED, 1949 e VOMOCIL, 1965). Para tensões de 0 a 400 cm de coluna de água, podem ser utilizados funis de placa porosa. A tensão máxima desse sistema é limitada pela porosidade da placa que permite a passagem do ar, quando a tensão tende a 400 cin de coluna de água (VOMOCIL, 1965 e REICHARDT, 1975). Acima desses limites de tensão, utiliza-se sistemas de placas porosas e membrana de Richards (RICHARDS e FIRE MAN, 1943).

Para a elaboração das curvas de retenção de água pelos procedimentos acima descritos, torna-se importante a determinação de densidade global do solo, para se obter os valores de umidade à base de volume. Essa propriedade do solo é obtida através da relação entre a massa seca e seu volume. em condições de campo. Sua determinação pode ser feita segundo vários métodos. No método do anel volumétrico, um anel de bordas cortantes é inserido cuidadosamente no solo e de lo retirado cheio; é muito utilizado, embora problemático em solos com presença de pedras. No método do 
cilindro de Uhland, um cilindro de alumínio no interior de uma armação de aço de bordas cortantes é intro duzido no solo por golpes de um martelo acoplado. Des crições mais detalhadas desses amostradores podem ser encontradas em LUTZ (1947) e JAMISON et azii (1950). No método da impermeabilização de torrões, pode-se utilizar parafina (TISDALL, 1951, citado por BLACK, 1965), solução de borracha (ABRDL e PALTA, 1968) ou ainda re sina saran (BRASCHER et alii, 1966) que oferece os melhores resultados. Estes métodos, segundo KIEHL (1979), levam a resultados superestimados.

Existem. ainda outros métodos, como o da escavação (BLACK, 1965) e o da atenuação da radiação gạ ma (van BAVEL et alii, 1957), tendo este último a vantagem de ñão perturbar a amostra e permitir acompanhar possíveis variações na densidade como o decorrer do tem po. Deve ser enfatizado que o conhecimento da densida de global é indispensável pará calcular a água disponí vel dos solos.

Os pesquisadores que estudam este aspecto da água no solo vêm tentando estabelecer relações entre a àgua retida no solo a um dado potencial ejos componentes do tamanho das partículas, sua natureza e teor de matéria orgánica, entre outros fatores. 
GROHMAN E MEOINA (1962) relataram que a quantidade de água retida pelo solo está na dependência do teor e natureza da fração argila e da porcentagem de matéria orgānica presente. P'ETERSEN et alii (1968), trabalhando com solos da Pennsylvania, encontraram correlação positiva entre a porcentagem de argila e as umidade volumétricas correspondentes às tensões $1 / 3$ e 15 atm. Para o carbono orgánico, a correlação só foi positiva para a umidade volumétrica a 15 atm. MacleAN e YAGER (1972) encontraram correlação positiva entre a umidade volumétrica e os teores de limo e carbono orgânico para as camadas superficiais e com.o teor de areia fina para as camadas mais profundas. RIVERS e SHIPP (1978) obtiveram correlação positiva entre a umidade volumétrica na capacidade de campo e as porcentagens de areia muito fina, limo e areia muito fina + limo + argila.

Existem dois pontos clásicos de umidade do solo: capacidade de campo e ponto de murchamento permanente.

A capacidade de campo corresponde a umidade atingida, sob condições de campo, por solos permeáveis, de textura e estrutura uniforme, inicialmente saturados, após sua drenagem livre. Isto, normalmente, acontece 48 a 72 horas após o fornecimento de água (VEIHMEYER e HENDRICKSON, 1949). Di versos pesquisadores têm procurado a melhor maneira de estimar 
a capacidade de campo em condições de laboratório. MARSHALL (1959) afirmou que não existe nenhum método de laboratório que possa ser um real substituto da determinação da capacidade de campo como acima definida, por vários fatores, entre eles, pro priedades físicas e condições iniciais de umidade do solo.

COLMAN (1947) encontrou valores de potencial ma tricial correspondentes à capacidade de campo que variaram de 50 a $350 \mathrm{~cm}$ de água, enquanto SMITH é B'RÓWNING (1947) encontraram valores entre 25 e 125 cm de água. Já RICHARDS (1949) encontrou valores intermediários dos encontrados pelos autores a cima, isto é, de 30 a $150 \mathrm{~cm}$ de água. Por outro lado, JAMI= SON (1956), trabalhando com diversos tipos de solo, encontrou variações num intervalo de 200 a $500 \mathrm{~cm}$ de água. Foi COLMAN (1947) que, trabalhando em condições de laboratório, encontrou evidências de que a capacidade de campo guardava estreita rela ção com a água retida a 0,33 atm, valor este que teve seu uso generalizado. Trabalhos posteriores ao de COLMÁN (1947) mostraram valores diferentes de 1/3 atm. Assim, JAMISON e KROTH (1958), trabalhando com amostras de 121 perfis, constataram que a sucÇão que mais se aproximava da capacidade de campo variou desde menos de 0,1 atm até mais de 1 atm. SALTER e HAWORTH (1961) mostraram correlação entre a capacidade de campo em solos francoarenosos e a umidade correspondente à tensão de $50 \mathrm{~cm}$ de água. A grande variabilidade dos valores encontrados mostra que a ca pacidade de campo nao e um ponto definido e universal de umida de correspondente a 0,33 atm, como é normalmente considerado. 
o ponto de murchamento permanente foi definido como sendo a umidade num solo onde a planta, em um certo estádio de seu desenvolvimento, murcha e, mesmo quando colocada em câmara escura e úmida, não recupera o turgor (VEIHMEYER e HENDRICKSON, 1949). Este ponto é normalmente considerado como a umidade dos solos correspondente à tensão de 15 atm. Isto se deve provavelmente a trabalhos como os de RICHARDS e WEAVER (1943) e ROBERTSON e KRONKE (1946) que encontraram valores pró ximos a 15 atm para diversos solos que estudaram. Deve ser enfatizado, no entanto, que este ponto clássico de umidade do sỏlo não depende só do estado de energia da água no solo, mas também da evapotranspiração real, da condutividade hidráulica, do volume de solo explorado pelas raizes, etc. (SLAVIK, 1974 , citado por PREVEDELLo, 1978).

Segundo VEIHMEYER e HENDRICKSON (1949), a água compreendida entre estes dois limites, capacidade de campo e ponto de murchamento permanente, foi definida como "ágiua dispo nível". A utilização de valores específicos para os limites inferior e superior de água disponível tem sido evitada na medida do possivel. Estes conceitos carecem de definições físi cas e não devem ser considerados como algo mais do que índices grosseiros (GARDNER, 1965), mesmo porque a ägua pode ser retirada pelas plantas abaixo e acima desses limites. De acordo com estes autores, no intervalo entre a capacidade de campo e ó ponto de murchamento permanente, a água é igualmente dispo nível e nele as atividades biológicas não são afetadas. 
RICHARDS e WALDLEIGH (1952), citados por REICHARDT (1975), encontraram evidências de que a diminuição do teor de água no solo diminui a disponibilidade, podendo a plan ta apresentar sintomas de deficiência de água antes de ser atingido o ponto de murchamento permanente. Discussões deta'Ihadas das relações solo-água-planta dentro deste intervalo de umidade dos solos podem ser encontrados em HAGAN (1957). FRAN MEIER et alii (1960) dividiram o intervalo de capacidade de água disponível em dois, chamando o sub-intervalo mais úmido de água prontamente disponível e o sub-intervalo mais seco de ágùa decrescentemente disponível.

A utilização da umidade correspondente a 0,33 atm como limite superior de água disponível parece levar a uma subestimação dos seus resultados. SALTER e HAWORTH (1961) sü gerem 0;05 atm e MCLEAN e YAGER (1972) 0,05 a 0,1 atm como valores mais adequados para valores de capacidade de campo.

Diversos autores procuraram correlacionar a á gua disponível com características físicas dos solos. JAMISON e DROTH (1958), trabalhando com solos do Missouri, obtiveram correlação negativa entre a porcentagem da fráção argila e a água disponível, considerando $1 / 3$ e 15 atm como limites. SALTER et alii (1968), utilizando os mesmos limites, já obtiveram correlação positiva entre as porcentagens de carbono orgânico e Iimo com a águà disponível. 
- PETERSEN et alii (1968) também encontraram correlação positiva entre a água disponível $(0,33$ e 15 atm) e a umidade volumétrica correspondente a 0,33 atm e a água disponí vel e a porcentagem da fração silte. Para as porcentagens de argila, areia. e umidade volumétrica a 15 atm, a correlação foi negativa. 


\title{
3. MATERIAL E METODOS
}

\author{
3.1. A A Área
}

\begin{abstract}
As amostras de solo utilizadas neste trabalho, foram coletadas da área do Projeto "Sistemas de Produção de Frü tas Tropicais", do Setor de Agro-Ecologia do Instituto Nacional de Pesquisas da Amazônia (INPA). Esta área, de dimensão $300 \times 400$ m, localiza-se à margem esquerda da Rodovia BR-174 (Manaus-Boa Vista), à altura do km 41 e pertence à Estação Experimental de Silvicultura Tropical do CNPq/INPA, Distrito Agropecuário da Superintendência da Zona Franca de Manaus, muni cípio de Manaus, Estado do Amazonas. Para facilidade de mape amento, ela foi dividida em quatro blocos de $100 \times 300 \mathrm{~m}$, e ca da bloco em 8. parcelas de $50 \times 75$ m (Figura 1).
\end{abstract}

\subsection{Solo}

O solo da região onde se encontra a área do pró jeto foi classificado por RANZANI (1979). Segundo este autor, 
existem dois tipos distintos de solo: um Latossolo Amarelo, e um Podzólico Vermelho-Amarélo. Pela classificação americana (E.U.A., 1975), o primeiro recebeu a denominação de Tipic Haplortox e o segundo de Orthoxic Tropohumult. Ambos possuem horizonte álico e horizonte A moderado, porém, o Latossolo é. de textura argilosa, proveniente da formação geológica Alter do Chão, enquanto que o Podzólico é de textura média, sedimentos fluviais não consolidados sobre a fórmação Alter do Chão. No Latossolo, o. relevo é ondulado curto com declividade de até $10 \%$, a drenagem é boa a moderada e observou-se ligeira erosão laminar. No Podzólico, o relevo é suave a ondulado, com declividade de até $18 \%$, a drenagem é boa e a erosão ausente.

\subsection{A Vegetação}

Sobre a área foram encontrados dois tipos distintos de vegetação: a mata arenícola e a mata argilícola, caracterizadas pela falta de acúmulo de húmus. Constituem uma estrutura complexa, com estratos dificilmente distinguíveis e folhas sempre verdes, encontrando-se elementos típicos de florestas tropicais pluviais, como sapopemas, cipós e grandes tre padeiras lenhosas, além de uma alta diversidade em espécies. A mata arenícola é caracterizada por uma estrutura não muito desenvolvida. 0 dossel atinge alturas compreendidas entre 12 e $20 \mathrm{~m}$ de altura, com espécies ocasionalmente emergentes, chegan do a atingir $25 \mathrm{~m}$ de altura. Existe uma abundāncia de árvores com copas pequenas e caules finos. Isto permite a pene- 
tração de grande luminosidade, o que facilita o desenvolvimento de palmeiras e ervas, tais como marantáceas e cyclantáceas. Sobre o solo existe uma manta grossa de raízes. A mata argilícola já possui uma estrutura bem mais desenvolvida. 0 dossel ocupa uma faixa na altura de 18 a $30 \mathrm{~m}$. As espécies emer - gentes chegam a atingir $35 \mathrm{~m}$. Existe uma dominância de árvores grandes com copas espalhadas, o que impede a penetração da. luz nos estratos inferiores. Por este motivo, estes estratos são menos densos e a manta de raízes é mais fina (ANDERSON, $1978)$.

\subsection{Projeto}

Inicialmente, a ärea em estudo era coberta pela vegetação nativa, Floresta Tropical Pluvial Primária. Para a instalação do campo experimental de frutíferas, a vegetação foi derrubaja no período compreendido entre agosto e outubro de 1976 e deixada secar sobre o solo, por um período mínimo de 45 dias. No mês de novembro, a área foi submetida ao fogo. Esta prática, apesar de destrutir a principal fonte de matéria orgânica para o solo, é bastante utilizada nas diversas regiões do trópico úmido, por ser imprescindível islash and burn agriculture) (NYE e GREENLAND, 1960).

Logo após a queima, teve início o inverno chuvo so: Fez-se, então, a semeadura da' leguminosa Desmodium intor tum, que teve por objetivo cobrir o solo o mais rápido possí- 
vel, para tentar minimizar os problemas de erosão. Em seguida, foram feitas as operações de estaqueamento e coveamento das parcelas. 0 coveamento e o plantio foram realizados durante os meses de janeiro e fevereiro de 1977. Ás espécies de frutíferas tropicais selecionadas para o projeto foram:

1. Graviola (Annona muricata, L.)

2. Caju (Anacardium occidentale, L.)

3. Biribá (Rolzinia mucosa Jacq.)

4. Coco (Cocus nucifera)

5. Pupunha (Guilielma gasipaes (HBK) Bailey)

6. Mapati (Pourouma cecropiaefolia Mart.).

\title{
3.5. As Amostras
}

\begin{abstract}
Na parte central de cada uma das 32 parcelas. foram abertas trincheiras a partir das quais foram retiradas amostras das camadas 0-20 cm, 20-40 cm e 40-60 cm de profundidade. Foram retiradas amostras com estrutura deformada para análise mecânica e de matéria orgânica, e. com estrutura não deformada para determinação de densidade global.
\end{abstract}

\subsubsection{Densidade Global}

A densidade global das camadas de solo de cada parcela foi considerada como sendo a média de duas amostragens tomadas em seu ponto médio. Para o cálculo deste parâmetro. 
foram utilizados cilindros de PVC, com uma extremidade cortante. Ds cilindros, cujo volume era $94,25 \mathrm{~cm}^{3}$ (diámetro $=5 \mathrm{~cm}$ e altura $=4,8 \mathrm{~cm}$ ), eram introduzidos na parede da trincheira através de pequena pressão e retirados cheios de solo. Uma vez retirado o excesso de solo de suas extremidades, o solo dos cí lindros era levado para a estufa a $110^{\circ} \mathrm{C}$, até que as amostras atingissem massa constante. A densidade global foi obtida a partir da relação:

$$
d_{g}=\frac{m_{s}}{v_{c}}
$$

onde: $\begin{aligned} d_{g} & =\text { densidade global }\left(\mathrm{g} \cdot \mathrm{cm}^{-3}\right) \\ m_{s} & =\text { massa do solo seco }(\mathrm{g}) \\ v_{c} & =\text { volume do cilindro }\left(\mathrm{cm}^{3}\right) .\end{aligned}$

3.5.2. Preparo das Amostras para Elaboração de Curvas Características

As amostras de solo com estrutura deformada, após terem sido retiradas das trincheiras, foram deixadas secar à sombra para em seguida sérem passadas por peneiras com maIhas de $2 \mathrm{~mm}$ de diàmetro, obtendo-se assim o que se chama Terra Fina Seca ao Ar (TFSA).

Para serem submetidas aos diferentes procedimen tos para medida de sua capacidade de retenção de água, e para 
que se obtiveșe uma melhor aproximação das condições de campo, as amostras foram acondicionadas em pequenos cilindros de alumínio (diâmetro $3,4 \mathrm{~cm}$ e altura $3,0 \mathrm{~cm}$ ), com o mesmo valor de densidade global obtido com as amostras de solo com estrutü ra indeformada. 0 cálculo da quantidade de solo a ser acondicionada em cada cilindro foi feito através da relação:

$$
m=(U+1) \cdot v_{c} \cdot d_{g}
$$

onde: $m=$ massa de TFSA $(g)$

$$
\begin{aligned}
& \mathrm{U}=\text { umidade da } \operatorname{TFSA}\left(\mathrm{g} \cdot \mathrm{g}^{-1}\right) \\
& \mathrm{v}_{\mathrm{C}}=\text { volume dos cilindros de alumínio }\left(\mathrm{cm}^{3}\right) \\
& \mathrm{d}_{\mathrm{g}}=\text { densidade global das amostras }\left(\mathrm{g} \cdot \mathrm{cm}^{-3}\right) .
\end{aligned}
$$

0 acondicionamento da massa de terra fina seca ao ar dentro dos cilindros de alumínio, para reprodução da den sidade global da amostra com estrutura indeformada, foi feita com auxílio de um bastão, cujo diâmetro era aproximadamente igual ao diâmetro do cilindro de alumínio.

\subsubsection{Retenção de Āgua pelas Amostras}

0 estudo da retenção de água pelas amostras de solo, acondicionadas da maneira acima descrita, foi feito atra vés de diversos meios, dependendo do valor da pressão à qual. a amostra era submetida. 
Para o estudo de retenção de água a alta tensão (15 atm), foi utilizada uma placa de Richards de 15 bar, com a respectiva câmara de pressão.

Para'médias tensões $(0,33$ e 1,0 atm $)$ foram utilizadas placas de Richards de 1 bar e a câmara de pressão de 5 bar. A leitura, nestes dois casos, foi feita nos manómetros constantes de cada conjunto.

Para a tensão de $60 \mathrm{~cm}$ de coluna de agua, foram utilizadas placas de 1 bar e a câmara de pressão de 5 bar. Co mo o manómetro não era suficientemente sensível para esta leitura, foi feita uma adaptação no sistema. Esta modificação consistiu em adaptar à câmara de pressão um manômetro de água. Dessa maneira, como pode ser observado na figura 2 , a pressão que está sendo imposta ao interior da câmara age por toda a sü perfície interna, inclusive sobre a da água presente no fundo da câmara de pressão. Através de um sistema de tubos de borracha flexível, essa água foi conectada a um tubo de vidro ver tical, que fica sobre uma escala graduada. Quando a câmara está aberta, a leitura é zero. Quando qualquer pressão for a Plicada no interior da câmara, esta é lida em cm de água na co luna vertical.

Para as ténsões de 30 e $2,5 \mathrm{~cm}$ de coluna de á gua, foi utilizada uma mesa para baixas tensões (Figura 3). E ta mesa difere da convencional por possuir nove pontos, atra- 
vés.dos quais a tensão é aplicada, ao invés de um. Os objetị vos de se colocar essas múltiplas saídas foi o de se obter um equilíbrio mais rápido e uma maior homogeneidade da tensão aplicada.

\subsubsection{Curvas Caracterīsticas de Retenção de Agua}

As curvas características de retenção de água foram construídas para cada uma das trés camadas estudadas de cada parcela. Elas foram elaboradas colocando-se a umidade volumétrica $\left(\mathrm{cm}^{3} \cdot \mathrm{cm}^{-3}\right)$ no eixo das abcissas e o potencial matricial (atm), em escala logarítmica, no eixo das ordenadas.

o cálculo da umidade volumétrica foi feito a partir da umidade à base de massa, através da relação:

$$
\Theta=U \cdot d_{g}
$$

onde: $\Theta=$ umidade volumétrica $\left(\mathrm{cm}^{3} \cdot \mathrm{cm}^{-3}\right)$

$$
\begin{aligned}
& U=\text { umidade à base de massa }\left(\mathrm{g} \cdot \mathrm{g}^{-1}\right) \\
& d_{g}=\text { densidade global }\left(\mathrm{g} \cdot \mathrm{cm}^{-3}\right) .
\end{aligned}
$$

3.5.5. Armazenagem e Capacidade de Água Disponível

O cálculo da armazenagem de água pelas camadas de solo de cada parcela foi feito pela seguinte expressao: 


$$
A=\Theta \cdot \Delta z
$$

onde: $A=$ armazenagem da camada (cm de água)

$$
\begin{aligned}
\Theta & =\text { umidade volumétrica da camada }\left(\mathrm{cm}^{3} \cdot \mathrm{cm}^{-3}\right) \\
\Delta z & =\text { espessura da camada }(\mathrm{cm}) .
\end{aligned}
$$

A capacidade de água disponível da camada nada mais é do que a variação de sua armazenagem entre dois limites pré-fixados de umidade, isto é:

$$
A D=\left(\theta_{s}-\theta_{i}\right) \Delta z
$$

onde: $A D=$ água disponível da camada (cm de água)

$\theta_{\mathbf{s}}=$ umidade volumétrica da camada no limite superior $\left(\mathrm{cm}^{3} \cdot \mathrm{cm}^{-3}\right)$

$\theta_{i}=$ umidade volumétrica da camada no limite inferior $\left(\mathrm{cm}^{3} \cdot \mathrm{cm}^{-3}\right)$

$\Delta_{z}=$ espessura da camada $(\mathrm{cm})$.

Tradicionalmente, considera-se como limite supe rior a umidade correspondente à tensão 0,33 atm e como limite inferior a correspondente a tensão 15 atm da curva característica.

No presente trabaltio, considerou-se a Água Disponível de.cada uma das três camadas de cada parcela, utilizan do-se estes limites tradicionais e também o valor de umidade 
correspondente à tensão 0,06 atm, para limite superior. A ca. pacidade de água disponível para todo o perfil (0-60 cm) foi obtida através da somatória de água disponível de cada camada.

\subsubsection{Umidade Adimensional}

Com o objetivo de homogeneizar os dados, estabe leceu-se a seguinte relação entre os valores de umidade porcen to em volume:

$$
\Omega_{i}=\frac{\theta_{i}-\theta_{15}}{\theta_{0,0025}-\theta_{15}}
$$

onde: $\Omega_{i}=$ valor adimensional de umidade volumétrica para um dado valor de $\Theta_{i}$

$\Theta_{i}=$ valor de umidade volumétrica correspondente a um potencial matricial de $i$ atm

$\Theta_{0,0025}=$ valor de umidade volumétrica correspondente ao potencial matricial de 0,0025 atm

$\Theta_{15}=$ valor de umidade volumétrica correspondente ao potencial matricial de 15 atm.

Desta maneira, todos os $\Omega_{0,0025}$ terão valores 1 e todos os $S_{15}$ terão valor zero.

Observando com mais detalhe a equação (6), vêse que, além de expressar a umidade adimensional, possui tam- 
bém um significado físico do ponto de vista de retenção de água, isto é :

a) $\left(\Theta_{i}-\theta_{15}\right) \Delta z=$ água retida na camada $\Delta z$ entre os limites i e 15 atm (equação 5 )

b) $\left(\Theta_{0,0025}-\Theta_{15}\right) \Delta z=$ água retida na camada $\Delta z$ entre os limites 0,0025 e 15 atm.

Dividindo-se (a) por (b), obtém-se a equação (6), que representa a fração da água existente na camada entre os limites 0,0025 e 15 atm, que é retida no intervalo i e 15 atm, quando o solo, estando inicialmerite com o valor de umidade correspondente a 0,0.025 atm, atinge, depois de certo tempo, - valor de umidade correspondente à tensão i. Evidentemente, a fração de água liberada ( $\lambda$ ) será, sob estas circunstâncias:

$$
\begin{gathered}
\lambda=1-\Omega, \ldots \ldots \ldots \ldots \ldots(7) \\
\text { Nestas circunstâncias, } \Omega_{0,33} \text { significa a fração }
\end{gathered}
$$
da água existente entre 0,0025 e 15 atm que está disponível pa ra a planta. 


\section{RESULTADOS E DISCUSSÃO}

Na Tabela 1 são encontrados os valores de densi dade global média das camadas 0-20 cm, $20-40 \mathrm{~cm}$ e 40-60 cm de profundidade, de todas as parcelas da área experimental. Cbserva-se, nesta tabela, que, em termos médios, existe uma tendência de aumento de densidade $\mathrm{com}^{\circ}$ a profundidade. Considerando que esta área nunca sofreu mecanização, é possível que esta tendência esteja ligada ao teor de matéria orgánica ao longo do perfil, o qual decresce com a profundidade (Tabela 2 ). Nota-se também que, para as camadas 0-20 cm e $20-40 \mathrm{~cm}$, o bloco IV apresenta maiores valores de densidade global do que os blocos I, II e III. Este fato pode ser atribuido à composição mecânica do solo, visto ser o bloco IV o de textura mais grossa da área, conforme pode ser visto nas Tabelas 3,4 e 5 . Com relação à camada 40-60 cm, não só o bloco IV, mas também o bloco II apresentam altos valores de densidade global. Por outro lado, pode-se observar ainda que o bloco II é o que apre senta os menores valores de densidade. Este bloco é o que a- 
presenta a textura mais fina da ärea (Tabelas 3,4 e 5).

As Tabelas 6,7 e 8 apresentam os dados de re tenção de água para as camadas 0-20 cm, 20-40 cm e 40-60 cm de profundidade, respectivamente.

Com os valores de umidade correspondentes às ten sões 0,33 e 15 atm destas tabelas e os valores das frações gra nulométricas apresentados nas Tabelas 3,4 e 5 , foram feitas análises de regressão linear cujos resultados são apresentados nas Tabelas 9 e 10.

A Tabela 9 mostra os valores de a (coeficiente

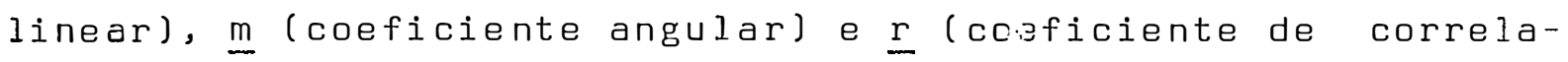
ção), obtidos da regressão linear entre a umidade volumétrica correspondente à tensão 0,33 atm e os componentes do tamanho de partículas (argila, argila + limo e argila + limo + areia fi na), para as camadas 0-20 cm, 20-40 cm e 40-60 cm de profundidade e para todo o perfil (0-60 cm de profundidade). Como pode ser observado nesta tabela, existe correlação significatí va entre os componentes da análise granulométrica e a umidade volumétrica à tensão de 0,33 atm. Percebe-se ainda que, com a profundidade, o coeficiente angular diminui, independentemente das frações granulométricas consideradas. Este fato pode ser considerado como uma menorr tendência à retenção de água das. ca madas mais profundas. Como o teor da matéria orgánica diminui com o aumento da profundidade (Tabela 2), pode-se inferir 
que. a diminuição da retenção de agua esteja ligada à diminuição deste componente. Apésar desta diferença entre as camadas, a regressão com todos os dados (o perfil todo) também foi altamente significativa, de tal maneira que se pode sugerir, para o perfil 0-60 cm de profundidade da área em questão, a equação 8, para calcular a umidade do solo correspondente à tensão 0,33 atm a partir do teor de argila:

$$
\Theta_{0,33}=0,0127+0,0043 \mathrm{~A} \%
$$

onde: $\Theta_{0,33}=$ umidade volumétrica $\left(\mathrm{cm}^{3} \cdot \mathrm{cm}^{-3}\right)$, correspondente à tensão 0,33 atm.

$A \%$ = teor de argila da amostra, em porcentagem.

A Tabela 10 é semelhante à Tabela 9, porém, a umidade é a correspondenté à tensão de 15 atm. Nela tambémse observa alta significáncia para todo o perfil e para as diversas camadas, porém, os coeficientes angulares são praticamente iguais, mostrando que para 15 atm a influência da matéria orgànica na retenção de água tornou-se negligível. A semelhança do que foi feito para a umidade correspondente à tensão 0,33 atm, a equação 9 pode ser sugerida para o cálculo da umidade volumétrica correspondente à tensão de 15 atm $\left(\Theta_{15}\right)$ a partir do teor de argila ( $A \%)$ da amostra para o perfil 0-60 cm da. área experimental:

$$
\theta_{15}=-0,0241+0,0041 \mathrm{~A} \%
$$


As Tabelas 11 e 12 apresentam os dados de água disponível para as camadas 0-20, 20-40 e 40-60 cm de profundidade, considerando-se como limite superior 0,33 e 0,06 atm, res pectivamente, e como limite inferior, $15 \mathrm{~cm}$. A partir dos resultados destas duas tabelas e dos de análise granulométrica das Tabelas 3,4 e 5, fizeram-se as análises de regressão line ar entre água disponível e os componentes do tamanho de partículas. Estes resultados estão nas Tabelas $13(0,33$ e 15 atm como limites de água disponível) e $14(0,06$ e 15 atm como limí tes de água disponívell.

Analisando-se os dados da Tabela 13 verifica-se que só houve significância para os dados da camada $0-20 \mathrm{~cm}$, is to é, para esta camada, o coeficiente de correlação é significativo ao nível de $1 \%$ Para as camadas 20-40 e 40-60 cm, no entanto, isto não se verifíca, mostrando que não existiu corre lação entre a água disponível e componente do tamanho de partí culas, ou seja, as retas são praticamente horizontais, mostran do que a água disponível não variou significativamente com a variação de $A, A+L$ e $A+L+A F$. Este fato pode estar, novamente, ligado ao teor de matéria orgânica, o qual é mais elevado na camada superficial. Estes resultados, entretanto, contrariam os obtidos por PETERSEN et alii (1968). Este fenómeno é comprovado pelos resultados apresentadas na Tabela 14, onde o coe ficiente de correlação só não foi significativo para a camada 40-60 cm. A significância também para a camada $20-40 \mathrm{~cm}$, neste caso onde os limites são 0,06 e 15 atm, em relação ao caso 
anterior onde estes limites eram 0,33 e 15 atm, deve estar relacionada com o aumento da faixa de água disponível para a par te mais úmida da curva de retenção. Os valores de umidade volumétrica correspondentes às tensões $0,06^{\circ}, 0,33$ e 15 atm, para as camadas $0-20,20-40$ e 40-60 cm de profundidade, foram plotados sobre um mapa da área. A união dos pontos de mesma umidade, através de iso-linhas, forneceram as Figuras 4 a 6,7 a 9 e 10 a 12, respectivamente. De maneira semelhante, para os dados de água disponível, considerando as umidade correspon dentes a 0,06 e 0,33 atm como limites superiores para as camadas 0-20, 20-40 e 40-60 cm, foram obtidas as Figuras 13-14, 1516 e 17-18, respectivamerite.

A análise das Figuras 4 a 6 mostra que, na camada 0-20 cm, o teor de água atinge o valor máximo na região das parcelas II-7 e II-8, enquanto que o mínimo é encontrado na re gião das parcelas IV-5 e IV-8. Este fato está relacionado com a classe textural, visto que a região das parcelas II-7 e II-8 é a mais argilosa da área e a das parcelas IV-5 a IV-8, a mais arenosa. Pode ser observada também uma grande alteração . nos valores de umidade na transição entre os blocos III e IV, através da aproximação entre as isolinhas, que só pode estár relacionada com a alteração na textura, isto é, a diminuição no teor de agua retida é uma consequência da textura que se torna mais grossa a medida que se caminha no bloco II em direção ao bloco IV (Tabela 3). Outro fato que merece ser ressal- 
tado é a semelhança entre as Figuras 5 e 6 , sendo uma praticamente o rebatimento da outra e com valores próximos de unidade. A explicação para este caso pode estar relacionada com o fato das tensões correspondentes a estas Figuras, 0,33 e 15 atm, estarem no ramo das curvas de retenção, onde grandes alte rações de tensão provocam pequenas alterações na umidade.

Com relação à água disponível na camada 0-20 cm (Figuras 13 e 14), observa-se que os seus valores mínimos estão na região das parcelas IV-5 a IV-8 para ambos os limites adotados, isto é, a região de mínima retenção de água é a de mínima água disponível. 0 mesmo não acontece com a parcela II-8, que apresenta a maior capacidade de retenção de água da área estudada, porém, não o maior valor de água disponível.

A explicação, mais uma vez, pode ser dada эtravés das classes texturais dos solos destas duas parcelas. 0 solo da parcela IV-7, por ser o mais arenoso da área, retém muito pouca água (Tabela 3) e já a baixas tensões a cede prati camente toda. Dessa maneira, quando este solo for submetido a tensões mais elevadas, não existirá mais água para ser cedida. Para o caso do solo da parcela II-8, o fato das curvas de retenção das amostras referentes à essa camada serem praticamente lineares e verticais no intervalo entre 0,06 e 15 atm, pode justificar o ocorrido.

Considerações semelhantes podem ser feitas para 
a camada 20-40 cm. Também as amostras de textura mais fina (II-8) e mais grossa (IV-6 e IV-8) são responsáveis pela máxima e mínima retenção de água da camada, respectivamente.

Com relação à água dispónível, o comportamento é bastante semejhante, visto que a parcela de menor retenção de água é a de mínima água disponível (IV-6 e IV-8), e a de má xima retenção não é a de máxima disponibilidade (II-8) (Figu$\operatorname{ras} 15$ e 16).

¿̇ comportamento das amostras da camada $40-60 \mathrm{~cm}$ de profundidade permịte consideraçães semelhantes àquelas feitas para as outras camadas (Figuras 17 e 18).

As Figuras 19, 20 e. 21 mostram as curvas características médias de retenção de água correspondentes a cada classe textural, para as camadas $0-20,20-40$ e 40-60 cm de pro fundidade, respectivamente. Pode ser observado que estas cur vas se comportam de acordo com as equações das Tabelas 9 e 10 , isto é, a retenção aumenta à medida que a textura se torna mais fina, ou seja, com o aumento do teor de argila.

Na camada 0-20 cm pode ser observado um paralelismo entre os trechos das curvas compreendidos entre 0,06 e 15 atm. A baixas tensões (menor que 0,06 atm), nota-se uma tendéncia de aumento dos valores absolutos das tangentesàs cur vas, conforme a textura se torna mais fina. 
Para a camada $20-40 \mathrm{~cm}$, podem ser feitas considerações semelhantes: Nesta, aparece uma classe textural (barrento), ausente na camada $0-20 \mathrm{~cm}$, cujo comportamento, sob o ponto de vista de retenção de água, corresponde ao esperado, ou seja, a sua curva característica ficou compreendida entre as das amostras de solo da classe areno-argilosa e argilosa. A tendência das tangentes para esta camada se apresenta de uma maneira menos acentuada.

As curvas características da camada $40-60 \mathrm{~cm}$ de profundidade apresentam um comportamento diferente das camadas superiores, no trecho correspondente às tensões 0,0025 e 0,06, atm, onde as curvas apresentam um faralelismo que se mantém até 15 atm.

Um fato que pode estar relacionado com o que se acabou de discutir para tensões abaixo de 0,06 atm é o do decréscimo do teor de matéria orgànica, a medida que se aprofunda no perfil de solo (Tabela 2).

As Tabelas 15,16 e 17 (correspondentes às cama das 0-20, 20-40 e 40-60 cm de profundidadel apresentam os valo res de $\Omega$ para as umidades correspondentes às tensões $0,03,0,0 \dot{6}$ 0,33 e 1 atm, obtidos a partir da equação 6 e 7 . A partir Jestas tabelas e das Tabelas 3 a 8 , calcularam-se os valores médios de $\Omega$ para. cada classe textural. Como o comportamento do que vamos explicar a seguir é semeihante para as três camadas, a- 
presentamos estes valores, e também os de $\lambda$, equação 7 , somente para a camada $0-20 \mathrm{~cm}$ (Tabela 18).

Como se pode notar na Tabela 18, à medida que a textura se torna mais grossa, menores frações de água são reti das, o que não quer dizer que maiores volumes de água tenham sido liberados. Como se trata de umidade volumétrica adimensionalizada, para se estimar o volume de água retido ou libera do, deve-se multiplicar os valores de $\delta$ e $\lambda$, respectivamente, pelo teor de água existente entre 0,0025 e 15 atm. No entantó, em termos comparativos, esta tabela ilustra claramente que a água do solo é mais facilmente liberada à medida que a textü ra se torna mais grossa. 


\section{CONCLUSÕES}

1. Independentemente do limite superior adotado $(0,06$ ou 0,33 atml para o cálculo de água disponível, os solos estudados apresentam baixa capacidade de água disponível.

2. As amostras que apresentaram mínima capacidade de retenção (as mais arenosas) apresentaram também capacidade mínima de água disponível. Para as de máxima retenção (as mais argilosas) não se verificou este comportamento.

3. Tendo em vista estas duas conclusões, a alta taxa de evapotranspiração e a alta intensidade das precipitações dessa região pode-se inferir que, com poucos dias sem precipitação, pode haver problemas de défíçe de água, enquanto que, nos períodos chuvosos, problemas ligados à erosão e perda dé nutrientes por lixiviação.

4. A elaboração de isolinhas de umidade e água disponível fornecem boa visualização do comportamento da água na á- 
rea.facilitando o reconhecimento do problema de uma maneira global. Portanto recomenda-se sua elaboração para áreas mai ores.

5. Informações sobre os valores de retenção e disponibilidade de água poderão ser obtidas através das seguin tes equações:

$$
\begin{aligned}
& \theta_{0,33}=0,0127+0,0043 \mathrm{~A} \% \\
& \theta_{15}=-0,0241+0,0041 \mathrm{~A} \%
\end{aligned}
$$

onde $\Theta_{0,33}$ e $\Theta_{15}$ são umidades volumétricas $\left(\mathrm{cm}^{3} \cdot \mathrm{cm}^{-3}\right)$, corres pondentes às tensões 0,33 e 15 atm, respectivamente, e $A \%$ é o teor de argila da amostra, em porcentagem. 
Tabela 1 - Densidade global $\left(\mathrm{g} . \mathrm{cm}^{-3}\right)$ das camadas 0-20, $20-40$ e 40-60 cm de profundidade de todas as parcelas.

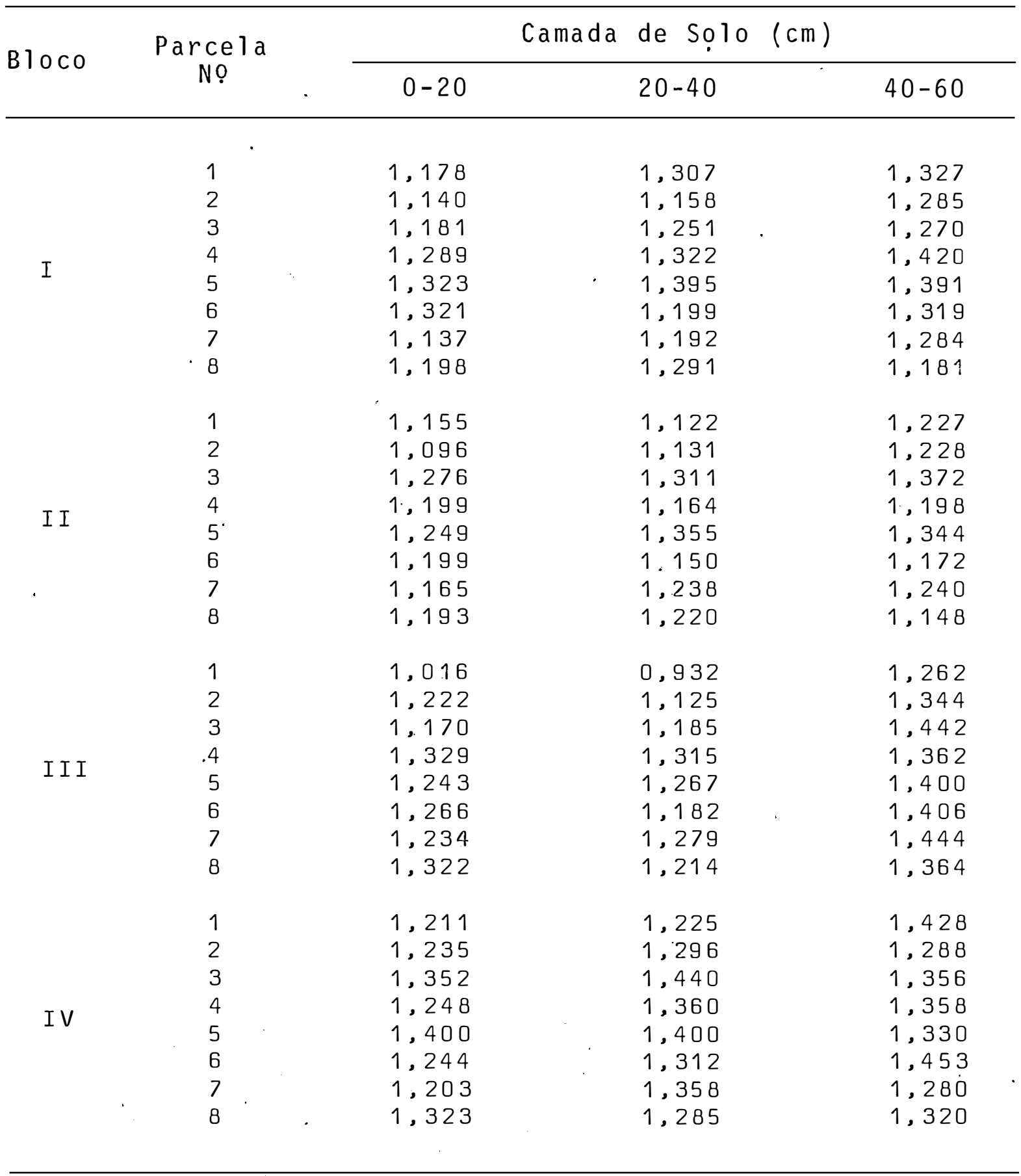


Tabela 2 - Teor de matéria orgānica (\%) das camadas 0-20, <040 e 40-60 cm de profundidade de todas as parce1 as.

\begin{tabular}{|c|c|c|c|c|}
\hline \multirow{2}{*}{ B 10co } & \multirow{2}{*}{ Parcela No } & \multicolumn{3}{|c|}{ Camada de Solo (cm) } \\
\hline & & $0-20$ & $20-40$ & $40-60$ \\
\hline \multirow{8}{*}{ I } & 1 & 1,1 & 0,5 & 0,4 \\
\hline & 2 & 2,1 & 0,7 & 0,4 \\
\hline & 3 & 1,7 & 0,7 & 0,4 \\
\hline & 4 & 1,0 & 0,4 & 0,3 \\
\hline & 5 & 1,4 & 0,7 & 0,5 \\
\hline & 6 & 1,9 & 0,7 & 0,2 \\
\hline & 7 & 1,8 & 1,2 & 0,7 \\
\hline & 8 & 1,3 & 0,8 & 0,4 \\
\hline \multirow{8}{*}{ I I } & 1 & 1,5 & 0,7 & 0,4 \\
\hline & 2 & 1,7 & 0,7 & 0,4 \\
\hline & 3 & 1,9 & 0,6 & 0,4 \\
\hline & 4 & 2,5 & $1 ., 1$ & 0,5 \\
\hline & 5 & 1,3 & 0,6 & 0,3 \\
\hline & 6 & 2,1 & 1,4 & 0,5 \\
\hline & 7 & 1,3 & 0,7 & 0,5 \\
\hline & 8 & 1,9 & 0,7 & 0,6 \\
\hline \multirow{8}{*}{ I I I } & 1 & 1,6 & 0,8 & 0,5 \\
\hline & 2 & 2,6 & 1,1 & 0,6 \\
\hline & 3 & 1,5 & 0,7 & 0,4 \\
\hline & 4 & 1,5 & 0,8 & 0,5 \\
\hline & 5 & 1,1 & 0,7 & 0,5 \\
\hline & 6 & 2,0 & $1,0$. & 0,7 \\
\hline & 7 & 1,4 & 1,0 & 0,7 \\
\hline & 8 & 3,4 & 1,4 & 1,0 \\
\hline \multirow{8}{*}{ IV } & 1 & 1,4 & 0,9 & 0,4 \\
\hline & 2 & 0,0 & 1,1 & 0,5 \\
\hline & 3 & 1,6 & 1,0 & 0,6 \\
\hline & 4 & 2,1 & 1,1 & 0,8 \\
\hline & 5 & 1,0 & 1,2 & 0,6 \\
\hline & 6 & 1,6 & 1,1 & 0,8 \\
\hline & 7 & 1,3 & 0,8 & 0,8 \\
\hline & 8 & 1,5 & 1,1 & 0,7 \\
\hline
\end{tabular}


Tabela 3 - Valor das porcentagens de areia, limo e argila e classe textural de todas as parcelas, para a camada $0-20 \mathrm{~cm}$ de profundidade.

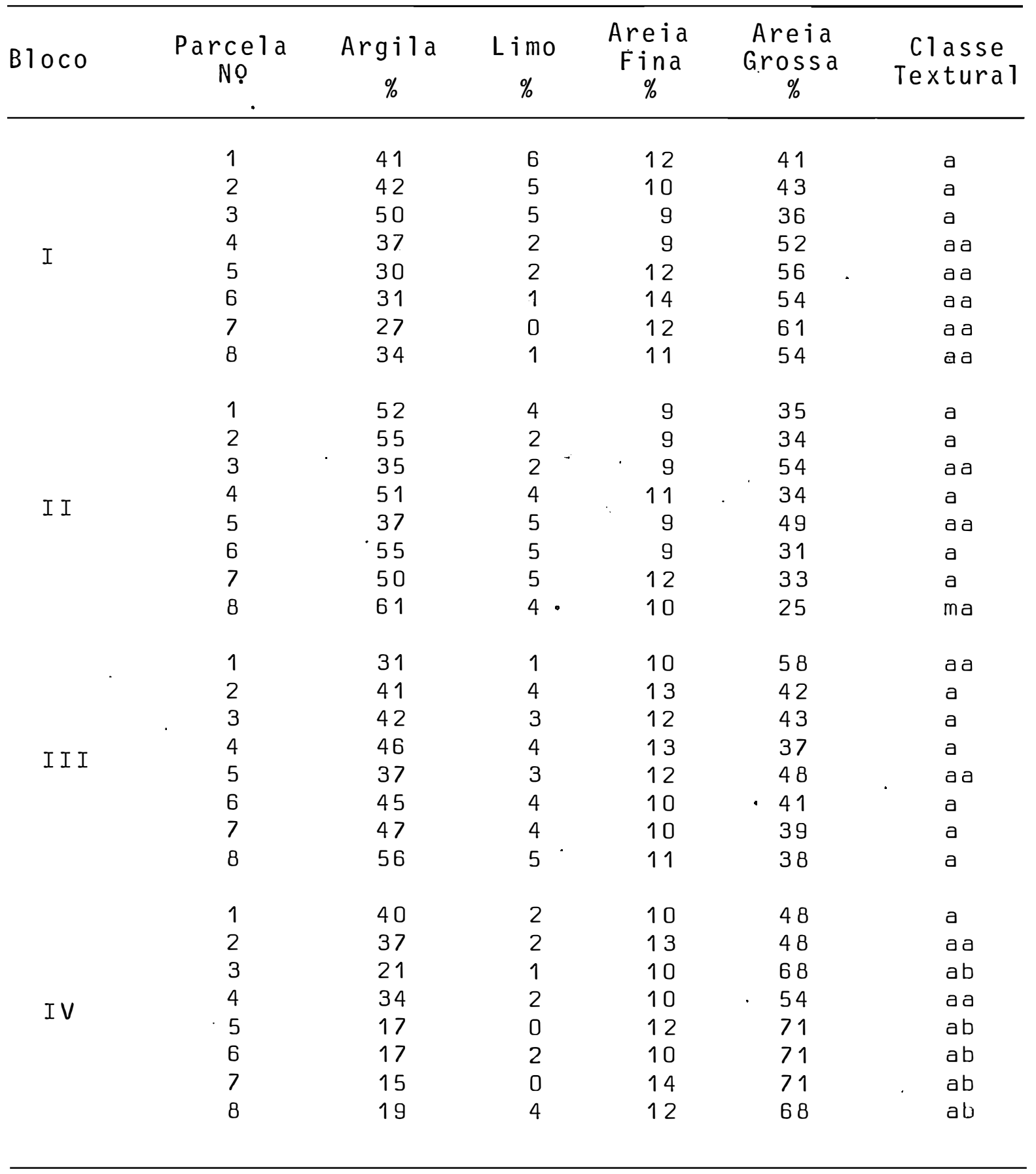


Tabela 4 - Valores das porcentagens de areia, limo e argila e classe textural de todas as parcelas, para a camada 20-40 cm de profundidade.

\begin{tabular}{|c|c|c|c|c|c|c|}
\hline Bloco & $\begin{array}{c}\text { Parcela } \\
\text { Nọ }\end{array}$ & $\underset{\%}{\operatorname{Argila}}$ & $\underset{\%}{\operatorname{Limo}}$ & $\begin{array}{c}\text { Areia } \\
\text { Fina } \\
\%\end{array}$ & $\begin{array}{c}\text { Areia } \\
\text { Grossa } \\
\%\end{array}$ & $\begin{array}{c}\text { Classe } \\
\text { Textural }\end{array}$ \\
\hline \multirow{8}{*}{ I } & 1 & 55 & 1 & 12 & 32 & $a$ \\
\hline & 2 & 57 & 5 & 7 & 31 & a \\
\hline & 3 & 61 & 5 & 8 & 26 & ma \\
\hline & 4 & 51 & 1 & 9 & 39 & a \\
\hline & 5 & 40 & 4 & 10 & 46 & a \\
\hline & 6 & 37 & 10 & 3 & 40 & a \\
\hline & 7 & 35 & 4 & 9 & 52 & аa \\
\hline & 8 & 40 & 5 & 9 & 46 & $a$ \\
\hline \multirow{8}{*}{ I I } & 1 & 62 & 4 & 8 & 26 & $\mathrm{ma}$ \\
\hline & 2 & 67 & 5 & 7 & 21 & $\mathrm{ma}$ \\
\hline & 3 & 51 & 4. & 8 & 37 & a \\
\hline & 4 & 59 & 6 & 9 & 26 & a \\
\hline & 5 & 56 & 4 & 10 & 30 & a \\
\hline & 6 & 61 & 5 & 9 & 25 & ma \\
\hline & 7 & 64 & 5 & 8 & 23 & $\mathrm{ma}$ \\
\hline & 8 & 66 & 6 & 8 & 20. & ma \\
\hline \multirow{8}{*}{ I I I } & 1 & 37 & 5 & 11 & 47 & а а \\
\hline & 2 & 51 & 5 & 10 & 34 & a \\
\hline & 3 & 37 & 5 & 12 & 44 & b \\
\hline & 4 & 56 & 4 & 10 & 30 & a \\
\hline & 5 & 45 & 1 & 15 & 39 & a \\
\hline & 6 & 52 & 4 & 11 & 33 & a \\
\hline & 7 & 60 & 1 & 8 & 31 & $\mathrm{ma}$ \\
\hline & 8 & 60 & 2 & 11 & 27 & ma \\
\hline \multirow{6}{*}{ IV } & 1 & 50 & 2 & 12 & 36 & a \\
\hline & 2 & 44 & 2 & 10 & 46 & a \\
\hline & 3 & 27 & 3 & 11 & 59 & аa \\
\hline & 4 & 45 & 2 & 10 & 43 & a \\
\hline & 5 & 25 & 1 & 10 & 64 & аa \\
\hline & 6 & 25 & 1 & 9 & 65 & aа \\
\hline \multirow[t]{2}{*}{. } & 7 & 27 & 2 & 19 & 52 & a a \\
\hline & 8 & 24 & 1 & 16 & 51 & ab \\
\hline
\end{tabular}


Tabela 5 - Valores das porcentagens de areia, limo e argila e classe textural de todas as parcelas, para a camada 40-60 cm de profundidade.

\begin{tabular}{|c|c|c|c|c|c|c|}
\hline Bloco & $\begin{array}{c}\text { Parcela } \\
\text { No }\end{array}$ & $\begin{array}{c}\text { Argila } \\
\%\end{array}$ & $\begin{array}{c}\text { L i mo } \\
\%\end{array}$ & $\begin{array}{c}\text { Areia } \\
\text { Fina } \\
\%\end{array}$ & $\begin{array}{c}\text { Areia } \\
\text { Grossa } \\
\%\end{array}$ & $\begin{array}{c}\text { Classe } \\
\text { Textural }\end{array}$ \\
\hline \multirow{8}{*}{ I } & 1 & 56 & 5 & 9 & 30 & a \\
\hline & 2 & 60 & 5 & 5 & 30 & $\mathrm{ma}$ \\
\hline & 3 & 67 & 5 & 6 & 22 & $\mathrm{ma}$ \\
\hline & 4 & 51 & 1 & . 10 & 38 & $a$ \\
\hline & 5 & 40 & 0 & 8 & 52 & a \\
\hline & 6 & 51 & 3 & 7 & 39 & a \\
\hline & 7 & 42 & 3 & 10 & 45 & a \\
\hline & 8 & 44 & 3 & 9 & 44 & a \\
\hline \multirow{8}{*}{ I I } & 1 & 65 & 2 & 7 & 26 & $\mathrm{ma}$ \\
\hline & 2 & 67 & 4 & 5 & 24 & $\mathrm{ma}$ \\
\hline & 3 & 51 & 4 & 8 & 37 & $a$ \\
\hline & 4 & 69 & 6 & 5 & 20 & $\mathrm{ma}$ \\
\hline & 5 & 59 & 3 & 9 & 29 & a \\
\hline & 6 & 69 & 5 & 5 & 21 & $\mathrm{ma}$ \\
\hline & 7 & 69 & 5 & 5 & 21 & $\mathrm{ma}$ \\
\hline & 8 & 79 & 6 & 5 & 10 & $\mathrm{ma}$ \\
\hline \multirow{8}{*}{ I I I } & 1 & 42 & 3 & 10 & 46 & a \\
\hline & 2 & 56 & 1 & 11 & 32 & $a$ \\
\hline & 3 & 54 & 2 & 10 & 34 & $a$ \\
\hline & 4 & 52 & 3 & 8 & 37 & $a$ \\
\hline & 5 & 52 & 0 & 12 & 36 & $a$ \\
\hline & 6 & 56 & 3 & 9 & 32 & a \\
\hline & 7 & 62 & 3 & 7 & 28 & ma \\
\hline & 8 & 65 & 2 & 10 & 23 & $\mathrm{ma}$ \\
\hline \multirow{8}{*}{ IV } & 1 & 54 & 1 & 8 & 37 & a \\
\hline & 2 & 54 & 2 & 8 & 36 & $a$ \\
\hline & 3 & 35 & 4 & 10 & 51 & a a \\
\hline & 4 & 47 & 5 & 9 & 39 & a \\
\hline & 5 & 25 & 0 & 12 & 63 & a a \\
\hline & 6 & 35 & 2 & 10 & 53 & a a \\
\hline & 7 & 22 & 0 & 14 & 64 & ab \\
\hline & 8 & 26 & 3 & 12 & 59 & aа \\
\hline
\end{tabular}


Tabela 6 - Valores de umidade volumétrica correspondentes às tensões 0,$0025 ; 0,03 ; 0,06 ; 0,33 ; 1$ e 15 atm de todas as parcelas, para a camada 0-20 cm de profundidade.

\begin{tabular}{|c|c|c|c|c|c|c|c|}
\hline \multirow{2}{*}{ Bloco } & \multirow{2}{*}{$\begin{array}{c}\text { Parcela } \\
\text { Nọ }\end{array}$} & & \multicolumn{4}{|c|}{ Tensão (Atm) } \\
\hline & & 0,0025 & 0,03 & 0,06 & 0,33 & 1 & 15 \\
\hline \multirow{8}{*}{ I } & 1 & 0,469 & 0,360 & 0,323 & 0,208 & 0,186 & 0,169 \\
\hline & 2 & 0,450 & 0,280 & 0,241 & 0,193 & 0,174 & 0,161 \\
\hline & 3 & 0,435 & 0,325 & 0,281 & 0,227 & 0,201 & 0,182 \\
\hline & 4 & 0,438 & 0,340 & 0,236 & 0,175 & 0,152 & 0,144 \\
\hline & 5 & 0,380 & 0,242 & 0,199 & 0,151 & 0,130 & 0,105 \\
\hline & 6 & 0,431 & 0,272 & 0,203 & 0,135 & 0,124 & 0,106 \\
\hline & 7 & 0,476 & 0,198 & 0,150 & 0,130 & 0,104 & 0,091 \\
\hline & 8 & 0,442 & 0,259 & 0,195 & 0,134 & 0,114 & 0,112 \\
\hline \multirow{8}{*}{ I I } & 1 & 0,472 & 0,339 & 0,302 & 0,242 & $0,21.8$ & 0,200 \\
\hline & 2 & 0,492 & 0,371 & 0,322 & 0,233 & 0,220 & 0,192 \\
\hline & 3 & 0,374 & 0,250 & 0,214 & 0,157 & 0,140 & 0,122 \\
\hline & 4 & 0,490 & 0,378 & 0,353 & 0,180 & 0,137 & 0,111 \\
\hline & 5 & 0,450 & 0,304 & 0,249 & 0,186 & 0,167 & 0,129 \\
\hline & 6 & 0,476 & 0,411 & 0,382 & 0,295 & 0,270 & 0,210 \\
\hline & 7 & 0,486 & 0,385 & 0,336 & 0,236 & 0,211 & 0,190 \\
\hline & 8 & 0,496 & 0,439 & 0,403 & 0,328 & 0,295 & 0,250 \\
\hline \multirow{8}{*}{ I I I } & 1 & 0,332 & 0,187 & 0,143 & 0,132 & 0,107 & 0,093 \\
\hline & 2. & 0,404 & 0,349 & 0,223 & 0,188 & 0,178 & 0,146 \\
\hline & 3 & 0,395 & 0,294 & 0,242 & 0,192 & 0,178 & 0,154 \\
\hline & 4 & 0,280 & 0,262 & 0,252 & 0,244 & 0,228 & 0,214 \\
\hline & 5 & 0,379 & 0,298 & 0,222 & 0,172 & 0,163 & 0,141 \\
\hline & 6 & 0,360 & 0,340 & 0,269 & 0,206 & 0,187 & 0,158 \\
\hline & 7 & 0,395 & 0,367 & 0,271 & 0,233 & 0,212 & 0,181 \\
\hline & 8 & 0,469 & 0,406 & 0,388 & 0,286 & 0,276 & 0,240 \\
\hline \multirow{8}{*}{ IV } & 1 & 0,330 & 0,219 & 0,173 & 0,119 & 0,113 & 0,101 \\
\hline & 2 & 0,360 & 0,214 & 0,143 & 0,096 & 0,093 & 0,063 \\
\hline & 3 & 0,253 & 0,137 & 0,095 & 0,064 & 0,048 & 0,044 \\
\hline & 4 & 0,354 & 0,317 & 0,292 & 0,197 & 0,189 & 0,169 \\
\hline & 5 & 0,316 & 0,133 & 0,070 & 0,065 & 0,061 & 0,041 \\
\hline & 6 & 0,287 & 0,124 & 0,080 & 0,065 & 0,060 & 0,044 \\
\hline & 7 & 0,292 & 0,111 & 0,069 & 0,063 & 0,060 & 0,044 \\
\hline & 8 & 0,299 & 0,161 & 0,141 & 0,130 & 0,121 & 0,107 \\
\hline
\end{tabular}


Tabela 7 - Valores de umidade volumétrica correspondentes às tensões 0,$0025 ; 0,03 ; 0,06 ; 0,33 ; 1$ e 15 atm de todas as parcelas, para a camada $20-40 \mathrm{~cm}$ de profund $\underline{i}$ dade.

\begin{tabular}{|c|c|c|c|c|c|c|c|}
\hline \multirow{2}{*}{ Bloco } & \multirow{2}{*}{$\begin{array}{c}\text { Parcela } \\
\text { Nọ }\end{array}$} & \multicolumn{6}{|c|}{ Tensão (Atm) } \\
\hline & & 0,0025 & 0,03 & 0,06 & 0,33 & 1 & 15 \\
\hline \multirow{8}{*}{ I } & 1 & 0,451 & 0,379 & 0,347 & 0,258 & 0,232 & 0,202 \\
\hline & 2 & 0,431 & 0,355 & 0,325 & 0,226 & 0,214 & 0,182 \\
\hline & 3 & 0,449 & 0,365 & 0,354 & 0,268 & 0,250 & 0,226 \\
\hline & 4 & 0,425 & 0,356 & 0,328 & 0,231 & 0,207 & 0,199 \\
\hline & 5 & 0,444 & 0,383 & 0,335 & 0,226 & 0,196 & 0,174 \\
\hline & 6 & 0,459 & 0,362 & 0,344 & 0,231 & 0,195 & 0,181 \\
\hline & 7 & 0,462 & 0,329 & 0,237 & 0,180 & 0,140 & 0,136 \\
\hline & 8 & 0,456 & 0,363 & 0,266 & 0,211 & 0,168 & 0,162 \\
\hline \multirow{8}{*}{ I I } & 1 & 0,516 & 0,415 & 0,345 & 0,284 & 0,254 & 0,234 \\
\hline & 2 & 0,537 & 0,457 & 0,406 & 0,297 & 0,265 & 0,253 \\
\hline & 3 & 0,464 & 0,447 & 0,373 & 0,226 & 0,218 & 0,214 \\
\hline & 4 & 0,512 & 0,413 & 0,369 & 0,288 & 0,262 & 0,240 \\
\hline & 5 & 0,466 & 0,440 & 0,382 & 0,307 & 0,277 & 0,255 \\
\hline & 6 & 0,532 & 0,455 & 0,399 & 0,318 & 0,268 & 0,254 \\
\hline & 7 & 0,512 & 0,448 & 0,416 & 0,321 & 0,289 & 0,263 \\
\hline & 8 & 0,486 & 0,470 & 0,404 & 0,323 & 0,297 & 0,285 \\
\hline \multirow{8}{*}{ I I I } & 1 & 0,285 & 0,225 & 0,171 & 0,146 & 0,130 & 0,110 \\
\hline & 2 & 0,376 & 0,326 & 0,276 & 0,218 & 0,207 & 0,175 \\
\hline & 3 & 0,328 & 0,289 & 0,239 & 0,199 & 0,179 & 0,161 \\
\hline & 4 & 0,389 & 0,346 & 0,323 & 0,276 & 0,250 & 0,230 \\
\hline & 5 & 0,373 & 0,340 & 0,282 & 0,212 & 0,193 & 0,177 \\
\hline & 6 & 0,363 & 0,251 & 0,214 & 0,190 & 0,178 & 0,150 \\
\hline & 7 & 0,386 & 0,345 & 0,266 & 0,240 & 0,210 & 0,178 \\
\hline & 8 & 0,459 & 0,371 & 0,275 & 0,238 & 0,218 & 0,194 \\
\hline \multirow{8}{*}{ IV } & 1 & 0,338 & 0,280 & 0,228 & 0,195 & 0,159 & 0,115 \\
\hline & 2 & 0,330 & 0,289 & 0,201 & 0,156 & 0,140 & 0,104 \\
\hline & 3 & 0,366 & 0,260 & $0 ; 133$ & 0,117 & 0,101 & 0,073 \\
\hline & 4 & 0,263 & 0,234 & 0,195 & 0,183 & 0,159 & $0, .121$. \\
\hline & 5 & 0,263 & 0,212 & 0,163 & 0,101 & 0,096 & 0,091 \\
\hline & 6 & 0,287 & 0,178 & 0,116 & 0,080 & 0,064 & 0,060 \\
\hline & 7 & 0,262 & 0,158 & 0,119 & 0,092 & 0,085 & 0,066 \\
\hline & 8 & 0,262 & 0,156 & 0,113 & 0,099 & 0,095 & 0,076 \\
\hline
\end{tabular}


Tabela 8 - Valores de umidade volumétrica correspondentes às tensões 0,$0025 ; 0,03 ; 0,06 ; 0,33 ; 1$ e 15 atm de todas as parcelas, para a camada 40-60 cm de profundidade.

\begin{tabular}{|c|c|c|c|c|c|c|c|}
\hline \multirow{2}{*}{ B $10 \mathrm{CO}$} & \multirow{2}{*}{$\begin{array}{c}\text { Parcela } \\
\text { Nọ }\end{array}$} & \multicolumn{6}{|c|}{ Tensão (Atm) } \\
\hline & & 0,0025 & 0,03 & 0,06 & 0,33 & 1 & 15 \\
\hline \multirow{8}{*}{ I } & 1 & 0,431 & 0,334 & 0,306 & 0,259 & 0,248 & 0,212 \\
\hline & 2 & 0,421 & 0,359 & 0,349 & 0,284 & 0,269 & 0,238 \\
\hline & 3 & 0,438 & 0,349 & 0,339 & 0,287 & 0,269 & 0,243 \\
\hline & 4 & 0,431 & 0,343 & 0,318 & 0,254 & 0,237 & 0,213 \\
\hline & 5 & 0,425 & 0,267 & 0,234 & 0,186 & 0,165 & 0,146 \\
\hline & 6 & 0,464 & 0,314 & 0,298 & 0,243 & 0,228 & 0,198 \\
\hline & 7 & 0,453 & 0,322 & 0,264 & 0,213 & 0,196 & 0,168 \\
\hline & 8 & 0,437 & 0,297 & 0,225 & 0,175 & 0,157 & 0,138 \\
\hline \multirow{8}{*}{ I I } & 1 & 0,496 & 0,420 & 0,351 & 0,292 & 0,277 & 0,245 \\
\hline & 2 & 0,512 & 0,399 & 0,365 & 0,309 & 0,289 & 0,265 \\
\hline & 3 & 0,457 & 0,372 & 0,322 & 0,254 & 0,233 & 0,211 \\
\hline & 4 & 0,504 & 0,393 & 0,356 & 0,303 & 0,286 & 0,262 \\
\hline & 5 & 0,472 & 0,365 & 0,349 & 0,294 & 0,275 & 0,255 \\
\hline & 6 & 0,511 & 0,387 & 0,336 & 0,288 & 0,266 & 0,252 \\
\hline & 7 & 0,497 & 0,415 & 0,389 & 0,320 & 0,300 & 0,273 \\
\hline & 8 & 0,477 & 0,438 & 0,401 & 0,333 & 0,309 & 0,280 \\
\hline \multirow{8}{*}{ I I I } & 1 & 0,394 & 0,338 & 0,288 & 0,218 & 0,194 & 0,170 \\
\hline & 2 & 0,431 & 0,384 & 0,341 & 0,278 & 0,254 & 0,226 \\
\hline & 3 & 0,394 & 0,345 & 0,319 & 0,261 & 0,234 & 0,212 \\
\hline & 4 & 0,410 & 0,370 & 0,336 & $0,267^{\circ}$ & 0,241 & 0,215 \\
\hline & 5 & 0,421 & 0,392 & 0,325 & 0,244 & 0,221 & 0,197 \\
\hline & 6 & 0,395 & 0,364 & 0,312 & 0,257 & 0,236 & 0,205 \\
\hline & 7 & 0,401 & 0,350 & 0,309 & 0,245 & 0,227 & 0,196 \\
\hline & 8 & 0,454 & 0,377 & 0,346 & 0,285 & 0,262 & 0,237 \\
\hline \multirow{8}{*}{ IV } & 1 & 0,334 & 0,291 & 0,241 & 0,186 & 0,157 & 0,133 \\
\hline & 2 & 0,341 & 0,297 & 0,245 & 0,188 & 0,173 & 0,144 \\
\hline & 3 & 0,341 & 0,221 & 0,178 & 0,115 & 0,096 & 0,072 \\
\hline & 4 & 0,341 & 0,308 & 0,251 & 0,163 & 0,137 & 0,105 \\
\hline & 5 & 0,261 & 0,212 & 0,154 & 0,102 & 0,089 & 0,066 \\
\hline & 6 & 0,265 & 0,224 & 0,177 & 0,120 & 0,100 & 0,076 \\
\hline & 7 & 0,284 & 0,217 & 0,173 & 0,133 & 0,098 & 0,072 \\
\hline & 8 & 0,297 & 0,238 & 0,197 & 0,137 & 0,119 & $0,0.91$ \\
\hline
\end{tabular}


Tabela 9 - Correlações lineares entre umidade volumétrica cor respondente à tensão de $1 / 3 \mathrm{~atm}$ e componentes do tamanho de partículas $(A=\operatorname{argila} ; A+L=\operatorname{argila}+$ limo e $A+L+A F=\operatorname{argila}+1 i m o+$ areia fina), para as camadas 0-20, 20-40 e 40-60 cm de profundidade e para todo o perfil $(0-60 \mathrm{~cm})$ da àrea experimental.

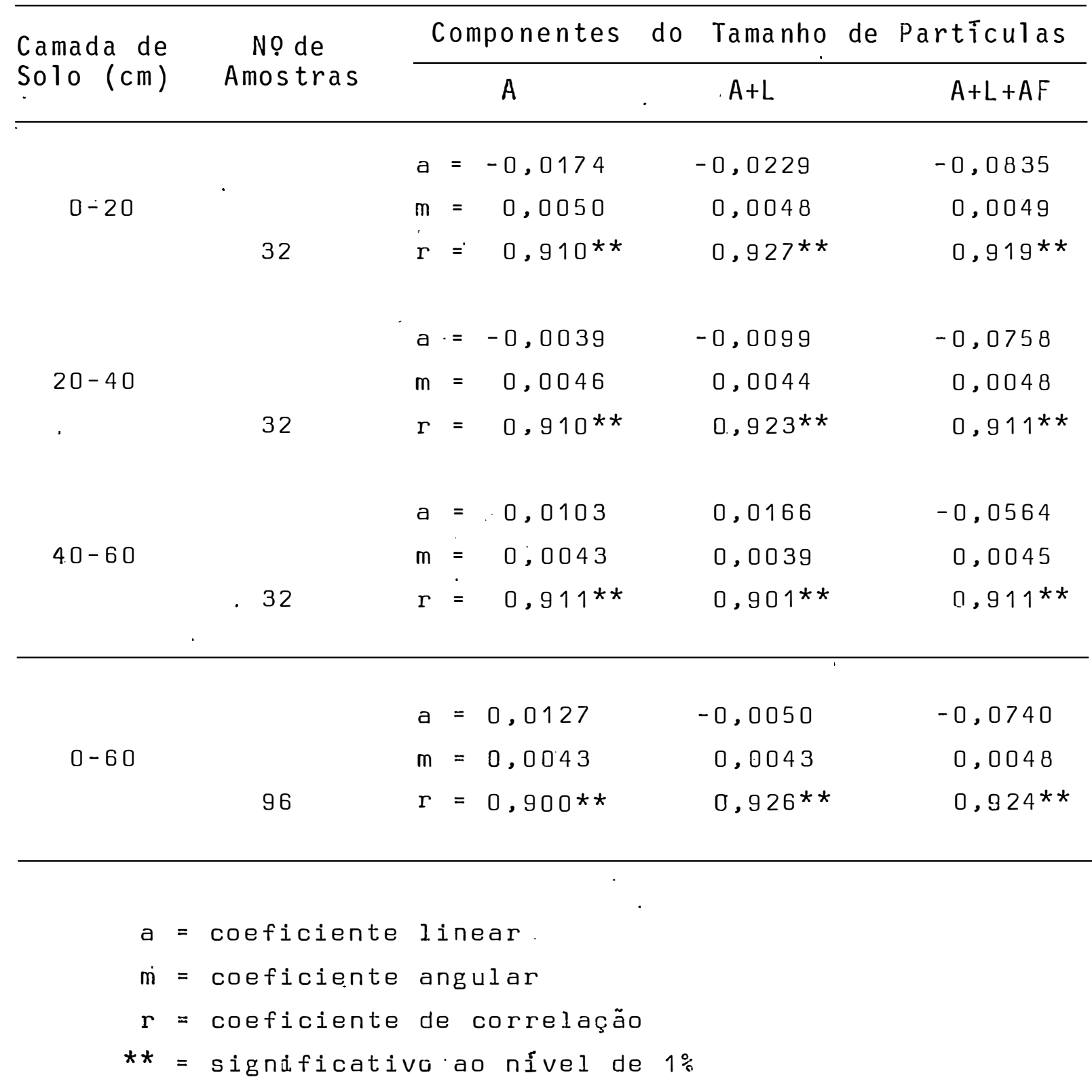


Tabela 10 - Correlações lineares entre umidade volumétrica cor respondente à tensão de $15 \mathrm{~atm}$ e componentes do ta manho de partīculas $(A=\operatorname{argila}, A+L=\operatorname{argila}+1 \underline{i}$ mo, $A+L+A F=\operatorname{argila}+1 i m o+$ areia fina), para as camadas 0-20, 20-40 e 40-60 cm de profundidade e para todo o perfil $(0-60 \mathrm{~cm})$ da área experimental.

\begin{tabular}{|c|c|c|c|c|c|}
\hline \multirow{2}{*}{$\begin{array}{l}\text { Camada de } \\
\text { Solo (cm) }\end{array}$} & \multirow{2}{*}{$\begin{array}{c}\text { No de } \\
\text { Amostras }\end{array}$} & \multicolumn{2}{|r|}{ Componentes } & do Tamanho de & \multirow{2}{*}{$\frac{\text { Partículas }}{A+L+A F}$} \\
\hline & & & A & $A+L$ & \\
\hline \multirow{3}{*}{$0-20$} & & $a$ & $=-0,0202$ & $-0,0257$ & $-0,0755$ \\
\hline & & $\mathrm{m}$ & $=0,0041$ & 0,0039 & 0,0041 \\
\hline & 32 & $\mathrm{r}$ & $=0.881 * *$ & $0,901 * *$ & $0,895 * *$ \\
\hline \multirow{3}{*}{$20-40$} & & a & $=-0,0293$ & $-0,0395$ & $-0,0961$ \\
\hline & & $\mathrm{m}$ & $=0,0042$ & 0,0041 & 0,0044 \\
\hline & 32 & $\mathrm{r}$ & $=0,879 * *$ & $0,905 * *$ & $0,877 * *$ \\
\hline \multirow{3}{*}{$40-60$} & & a & $=-0,0362$ & $-0,0298$ & $-0,1021$ \\
\hline & & $\mathrm{m}$ & $=0,0043$ & 0,0039 & 0,0045 \\
\hline & 32 & $\mathrm{r}$ & $=0,909 * *$ & $0,900 * *$ & $0,907 * *$ \\
\hline \multirow{3}{*}{$0-60$} & & $a$ & $=-0,0241$ & $-0,0295$ & $-0,0900$ \\
\hline & & $\mathrm{m}$ & $=0,0041$ & 0,0040 & 0,0043 \\
\hline & 96 & $r$ & $=0,901 * *$ & $0,913 * *$ & $0,903 * *$ \\
\hline
\end{tabular}

\footnotetext{
$a=$ coeficiente linear

$m=$ coeficiente angular

$r=$ coeficiente de correlação

** = significativo ao nível de $1 \%$
} 
Tabela 11 - Valores de capacidade de água disponīvel (mm) das camadas 0-20, 20-40 e 40-60 cm de profundidade de todas as parcelas, considerando $1 / 3$ e 15 atm como 1 imites superior e inferior, respectivamente.

\begin{tabular}{|c|c|c|c|c|}
\hline \multirow{2}{*}{ B10Co } & \multirow{2}{*}{ Parcela No } & \multicolumn{3}{|c|}{ Camada de Solo (cm.) } \\
\hline & & $0-20$ & $20-40$ & $40-60$ \\
\hline \multirow{8}{*}{ I } & 1 & 7,8 & 11,2 & 9,4 \\
\hline & 2 & 6,4 & 8,8 & 9,2 \\
\hline & 3 & 9,0 & 8,4 & 8,8 \\
\hline & 4 & 6,2 & 6,4 & 8,2 \\
\hline & 5 & 9,2 & 10,4 & 8,0 \\
\hline & 6 & 5,8 & 10,0 & 7,0 \\
\hline & 7 & 7,8 & 8,8 & 9,0 \\
\hline & 8 & 4,4 & 9,8 & 7,4 \\
\hline \multirow{3}{*}{$\therefore$} & 1 & 8,4 & 10,0 & 9,4 \\
\hline & 2 & 8,2 & 8,8 & 8,8 \\
\hline & 3 & 7,0 & 2,4 & 8,6 \\
\hline \multirow{5}{*}{ I I } & 4 & 13,8 & 9,6 & 8,2 \\
\hline & 5 & 11,4 & 10,4 & 8,6 \\
\hline & 6 & 17,0 & 12,8 & 7,2 \\
\hline & 7 & 9,2 & 11,6 & 11,8 \\
\hline & 8 & 14,6 & 7,6 & 10,6 \\
\hline \multirow{8}{*}{ I I I } & 1 & 7,8 & 7,2 & 9,6 \\
\hline & 2 & 8,4 & 8,6 & 10,2 \\
\hline & 3 & 7,6 & 7,6 & 9,8 \\
\hline & 4 & 6,0 & 9,2 & 10,4 \\
\hline & 5 & 6,2 & 7,0 & 9,4 \\
\hline & 6 & 9,6 & 8,0 & 10,4 \\
\hline & 7 & 10,4 & 12,4 & 9,8 \\
\hline & 8 & 9,2 & 8,8 & 9,6 \\
\hline \multirow{8}{*}{ IV } & 1 & 3,6 & 16,0 & 10,6 \\
\hline & 2 & 6,6 & 10,4 & 8,8 \\
\hline & 3 & 4,0 & 8,8 & 8,6 \\
\hline & 4 & 5,6 & 12,4 & 11,6 \\
\hline & 5 & 4,8 & 3,6 & 7,2 \\
\hline & 6 & 4,2 & 4,0 & 8,8 \\
\hline & 7 & 3,8 & 16,4 & 8,2 \\
\hline & 8 & 4,6 & 4,6 & 9,2 \\
\hline
\end{tabular}


Tabela 12 - Valores de capacidade de ägua disponível (mm) das camadas 0-20, 20-40 e 40-60 cm de profundidade de todas as parcelas, considerando 0,06 e 15 atm como limites superior e inferior, respectivamente.

\begin{tabular}{|c|c|c|c|c|}
\hline \multirow{2}{*}{ B $10 \mathrm{CO}$} & \multirow{2}{*}{ Parcella No } & \multicolumn{3}{|c|}{ Camada de Solo (cm) } \\
\hline & & $0-20$ & $20-40$ & $40-60$ \\
\hline \multirow{8}{*}{ I } & 1 & 18,8 & 29,0 & 18,8 \\
\hline & 2 & 22,2 & 34,6 & 22,2 \\
\hline & 3 & 19,8 & 25,6 & 18,0 \\
\hline & 4 & 18,4 & 25,8 & 21,0 \\
\hline & . 5 & 18,8 & 32,2 & 17,6 \\
\hline & 6 & 19,4 & 32,6 & 20,0 \\
\hline & 7 & 11,8 & 20,2 & 19,2 \\
\hline & 8 & 16,8 & 20,8 & 17,4 \\
\hline \multirow{8}{*}{ I I } & 1 & 20,4 & 22,2 & 21,2 \\
\hline & 2 & 26,0 & 30,6 & 20,0 \\
\hline & 3 & 18,4 & 31,8 & 22,2 \\
\hline & 4 & 48,4 & 25,8 & 18,8 \\
\hline & 5 & 24,0 & 25,4 & 18,8 \\
\hline & 6 & 34,4 & 29,0 & 16,8 \\
\hline & 7 & 29,2 & 30,6 & 23,2 \\
\hline & 8 & 29,6 & 23,8 & 24,2 \\
\hline \multirow{8}{*}{ I I I } & 1. & 10,0 & 12,2 & 23,6 \\
\hline & 2 & 15,4 & 20,2 & 23,0 \\
\hline & 3 & 17,6 & 15,6 & 21,4 \\
\hline & 4 & 7,6 & 18,6 & 24,2 \\
\hline & 5 & 16,2 & 21,0 & 25,6 \\
\hline & 6 & 22,2 & 12,8 & 21,4 \\
\hline & 7 & 18,0 & 17,6 & 22,6 \\
\hline & 8 & 29,8 & 16,2 & 21,8 \\
\hline \multirow{8}{*}{ IV } & 1 & 14,6 & 22,6 & 21,6 \\
\hline & 2 & 16,0 & 19,4 & 20,2 \\
\hline & 3 & 10,2 & 12,0 & 21,2 \\
\hline & 4 & 24,6 & 14,8 & 29,2 \\
\hline & 5 & 7,2 & 14,0 & 17,6 \\
\hline & 6 & 7,2 & 11,2 & 20,2 \\
\hline & 7 & 5,0 & 18,6 & 20,2 \\
\hline & 8 & 6,8 & 7,4 & $2 \cdot 1,2$ \\
\hline
\end{tabular}


Tabela 13 - Correlações lineares entre água disponível (1/3 e 15 atm como limites) e componentes do tamanho de particulas $(A=\operatorname{argila}, A+L=\operatorname{argila}+1 i m o, A+L+$ $A F=$ argila + limo + areia fina) para as camadas 0-20, 20-40 e 40-60 cm de profundidade da ārea experimental.

\begin{tabular}{|c|c|c|c|c|c|}
\hline \multirow{2}{*}{$\begin{array}{l}\text { Camada de } \\
\text { Solo (cm) }\end{array}$} & \multirow{2}{*}{$\begin{array}{c}\text { No de } \\
\text { Amostras }\end{array}$} & \multicolumn{4}{|c|}{ Componentes do Tamanho de Partículas } \\
\hline & & & $A$ & $A+L$ & $A+L+A F$ \\
\hline \multirow{3}{*}{$0-20$} & & a & $=0,7695$ & 0,6726 & $-1,4008$ \\
\hline & $\cdot$ & $\mathrm{m}$ & $=0,1816$ & 0,1701 & 0,1747 \\
\hline & 32 & $r$ & $=0,707 * *$ & $0,708 * *$ & $0,696 * *$ \\
\hline \multirow{3}{*}{$20-40$} & & $a$ & $=6,3128$ & 6,3248 & 4,6012 \\
\hline & & $\mathrm{m}$ & $=0,0586$ & 0,0545 & 0,0738 \\
\hline & 32 & $r$ & $=0,249$ & ?. 245 & 0,303 \\
\hline \multirow{3}{*}{$40-60$} & & a & $=9,1167$ & 0,0034 & 9,3501 \\
\hline & & $\mathrm{m}$ & $=0,0064$ & 9,2600 & 0,0016 \\
\hline & 32 & $r$ & $=0,045$ & 0,026 & 0,010 \\
\hline
\end{tabular}

$\begin{aligned} a & =\text { coeficiente linear } \\ m & =\text { coeficiente angular } \\ r & =\text { coeficiente de correlação } \\ * * & =\text { significativo ao nível de } 1 \%\end{aligned}$


Tabela 14 - Correlações lineares entre àgua disponīvel (0,06 e 15 atm como limites) e componentes de tamanho de particulas $(A=\operatorname{argila}, A+L=\operatorname{argila}+1 i m o, A+L+$ $A F=\operatorname{argila}+1 i m o+$ areia fina) para as camadas 0-20, 20-40 e 40-60 cm de profundidade da área experimental.

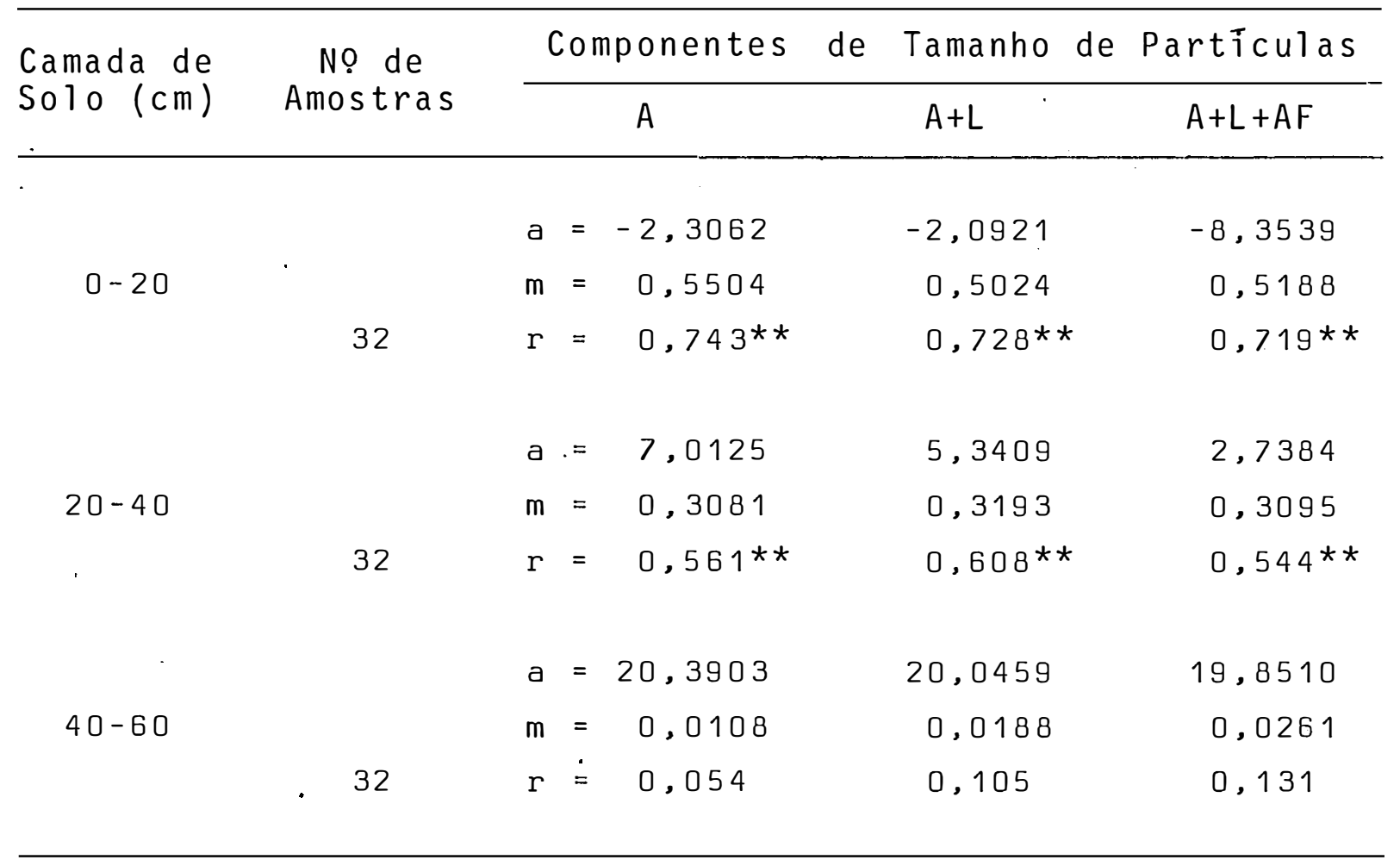

$$
\begin{aligned}
a & =\text { coeficiente linear } \\
m & =\text { coeficiente angular } \\
r & =\text { coeficiente de correlação } \\
* * & =\text { significativo ao nível de } 1 \%
\end{aligned}
$$


Tabela 15 - Valores de umidade adimensional correspondentes às tensões 0,0025;0,03;0,06;0,33;1 e 15 atm, de todas as parcelas, para a camada $0-20 \mathrm{~cm}$ de profun didade.

\begin{tabular}{|c|c|c|c|c|c|c|c|}
\hline \multirow{2}{*}{ Bloco } & \multirow{2}{*}{$\begin{array}{c}\text { Parcela } \\
\text { No }\end{array}$} & \multicolumn{6}{|c|}{ Tensão (Atm) } \\
\hline & & 0,0025 & 0,03 & 0,06 & 0,33 & 1 & 15 \\
\hline \multirow{8}{*}{ I } & 1 & 1 & 0,64 & 0,51 & 0,13 & 0,06 & 0 \\
\hline & 2 & 1 & 0,41 & 0,28 & 0,11 & 0,04 & 0 \\
\hline & 3 & 1 & 0,56 & 0,39 & 0,18 & 0,07 & 0 \\
\hline & 4 & 1 & 0,66 & 0,31 & 0,10 & 0,03 & 0 \\
\hline & 5. & 1 & 0,51 & 0,30 & 0,12 & 0,06 & 0 \\
\hline & 6 & 1 & 0,28 & 0,15 & 0,10 & 0,03 & 0 \\
\hline & 7 & 1 & 0,28 & 0,15 & 0,10 & 0,03 & 0 \\
\hline & 8 & 1 & $0,4 \dot{4}$ & 0,25 & 0,07 & 0,01 & 0 \\
\hline \multirow{8}{*}{ II I } & 1 & 1 & 0,51 & 0,37 & 0,15 & 0,07 & 0 \\
\hline & 2 & 1 & 0,60 & 0,43 & 0,14 & 0,09 & 0 \\
\hline & 3 & 1 & 0,51 & 0,36 & 0,14 & 0,09 & 0 \\
\hline & 4 & 1 & 0,70 & 0,64 & 0,18 & 0,07 & 0 \\
\hline & 5 & 1 & 0,54 & 0,37 & 0,17 & 0,12 & 0 \\
\hline & 6 & 1 & 0,75 & 0,64 & 0,32 & 0,22 & 0 \\
\hline & 7 & 1 & 0,66 & 0,49 & 0,15 & 0,07 & 0 \\
\hline & 8 & 1 & 0,74 & 0,61 & 0,30 & 0,16 & 0 \\
\hline \multirow{8}{*}{ I I I } & 1 & 1 & 0,39 & 0,21 & 0,16 & 0,06 & 0 \\
\hline & 2 & 1 & 0,90 & 0,30 & 0,16 & 0,12 & 0 \\
\hline & 3 & 1 & 0,58 & 0,36 & 0,16 & 0,10 & 0 \\
\hline & 4 & 1 & 0,72 & 0,58 & $0,45$. & 0,21 & 0 \\
\hline & 5 & 1 & 0,66 & 0,34 & 0,13 & 0,09 & 0 \\
\hline & 6 & 1 & 0,90 & 0,55 & 0,24 & 0,14 & 0 \\
\hline & 7 & 1 & 0,87 & 0,42 & 0,20 & 0,14 & 0 \\
\hline & 8 & 1 & 0,72 & 0,65 & 0,20 & 0,16 & 0 \\
\hline \multirow{8}{*}{ IV } & 1 & 1 & 0,52 & 0,31 & 0,09 & 0,08 & 0 \\
\hline & 2 & 1 & 0,51 & 0,27 & 0,11 & 0,10 & 0 \\
\hline & 3 & 1 & 0,44 & 0,24 & 0,10 & 0,02 & 0 \\
\hline & 4 & 1 & 0,80 & 0,66 & 0,15 & 0,11 & 0 \\
\hline & 5 & 1 & 0,33 & 0,12 & 0,09 & 0,07 & 0 \\
\hline & 6 & $\cdot 1$ & 0,32 & 0,15 & 0,09 & 0,07 & 0 \\
\hline & 7 & 1 & 0,23 & 0,10 & 0,08 & 0,06 & 0 \\
\hline & 8 & 1 & 0,28 & 0,18 & 0,12 & 0,07 & 0 \\
\hline
\end{tabular}


Tabela 16 - Valores de umidade adimensional correspondentes às tensões 0,0025;0,03;0,06;0,33; 1 e 15 atm de to das as parcelas para a camada $20-40 \mathrm{~cm}$ de profund $\underline{i}$ dade.

\begin{tabular}{|c|c|c|c|c|c|c|c|}
\hline \multirow{2}{*}{ Bloco } & \multirow{2}{*}{$\begin{array}{c}\text { Parcela } \\
\text { No }\end{array}$} & \multicolumn{6}{|c|}{ Tensão (Atm) } \\
\hline & & 0,0025 & 0,03 & 0,06 & 0,33 & 1 & 15 \\
\hline \multirow{8}{*}{ I } & 1 & 1 & 0,71 & 0,51 & $0,2 \dot{2}$ & 0,12 & 0 \\
\hline & 2 & 1 & 0,61 & 0,57 & 0,19 & 0,13 & 0 \\
\hline & 3 & 1 & 0,62 & 0,57 & 0,19 & 0,11 & 0 \\
\hline & 4 & 1 & 0,69 & 0,57 & 0,14 & 0,02 & 0 \\
\hline & 5. & 1 & 0,77 & 0,60 & 0,19 & 0,08 & 0 \\
\hline & 6 & 1 & 0,65 & 0,58 & 0,18 & 0,05 & 0 \\
\hline & 7 & 1 & 0,59 & 0,31 & 0,13 & 0,01 & 0 \\
\hline & 8 & 1 & 0,68 & 0,35 & 0,12 & 0,02 & 0 \\
\hline \multirow{8}{*}{ I I } & 1 & 1 & 0,64 & 0,39 & 0,18 & 0,07 & 0 \\
\hline & 2 & 1 & 0,71 & 0,54 & 0,15 & 0,04 & 0 \\
\hline & 3 & 1 & 0,93 & 0,64 & 0,05 & 0,02 & 0 \\
\hline & 4 & 1 & 0,64 & 0,47 & 0,18 & 0,08 & 0 \\
\hline & 5 & 1 & 0,88 & 0,60 & 0,25 & 0,10 & 0 \\
\hline & 6 & 1 & 0,72 & 0,52 & 0,23 & 0,05 & 0 \\
\hline & 7 & 1 & 0,74 & 0,61 & 0,23 & 0,10 & 0 \\
\hline & 8 & 1 & 0,92 & 0,59 & 0,19 & 0,06 & 0 \\
\hline \multirow{8}{*}{ I I I } & 1 & 1 & 0,66 & 0,35 & 0,21 & 0,11 & 0 \\
\hline & 2 & 1 & 0,75 & 0,50 & 0,21 & 0,16 & 0 \\
\hline & 3 & 1 & 0,77 & 0,47 & 0,23 & 0,11 & 0 \\
\hline & 4 & 1 & 0,73 & 0,58 & 0,29 & 0,13 & 0 \\
\hline & 5 & 1 & 0,83 & 0,54 & 0,18 & 0,08 & 0 \\
\hline & 6 & 1 & 0,47 & 0,30 & 0,19 & 0,13 & 0 \\
\hline & 7 & 1 & 0,80 & 0,42 & 0,30 & 0,15 & 0 \\
\hline & 8 & 1 & 0,67 & 0,31 & 0,17 & 0,09 & 0 \\
\hline \multirow{8}{*}{ IV } & 1 & 1 & 0,74 & 0,51 & 0,36 & 0,20 & 0 \\
\hline & 2 & 1 & 0,82 & 0,52 & 0,23 & 0,16 & 0 \\
\hline & 3 & 1 & 0,64 & 0,21 & 0,15 & 0,10 & 0 \\
\hline & 4 & 1 & 0,80 & 0,52 & 0,44 & 0,27 & 0 \\
\hline & 5 & 1 & 0,70 & 0,41 & 0,05 & 0,02 & 0 \\
\hline & 6 & 1 & 0,52 & 0,25 & 0,09 & 0,02 & 0 \\
\hline & 7 & 1 & 0,47 & 0,27 & 0,13 & 0,10 & 0 \\
\hline & 8 & 1 & 0,42 & 0,20 & 0,12 & 0,10 & 0 \\
\hline
\end{tabular}


Tabela 17 - Valores de umidade adimensional correspondentes às tensões 0,$0025 ; 0,03 ; 0,06 ; 0,33 ; 1$ e 15 atm, de todas as parcelas para a camada 40-60 cm de profun didade.

\begin{tabular}{|c|c|c|c|c|c|c|c|}
\hline \multirow{2}{*}{ B1 oco } & \multirow{2}{*}{$\begin{array}{c}\text { Parcela } \\
\text { No }\end{array}$} & \multicolumn{6}{|c|}{ Tensão (Atm) } \\
\hline & & 0,0025 & 0,03 & 0,06 & 0,33 & 1 & 15 \\
\hline \multirow{8}{*}{ I } & 1 & 1 & 0,56 & 0,43 & 0,21 & 0,14 & 0 \\
\hline & 2 & 1 & 0,66 & 0,61 & 0,25 & 0,17 & 0 \\
\hline & 3 & 1 & 0,54 & 0,49 & 0,23 & 0,13 & 0 \\
\hline & 4 & 1 & 0,59 & 0,48 & 0,19 & 0,11 & 0 \\
\hline & 5 & 1 & 0,43 & 0,31 & 0,14 & 0,07 & 0 \\
\hline & 6 & 1 & 0,44 & 0,38 & 0,17 & 0,11 & 0 \\
\hline & 7 & 1 & 0,51 & 0,46 & 0,26 & 0,10 & 0 \\
\hline & 8 & 1 & 0,53 & 0,29 & 0,12 & 0,06 & 0 \\
\hline \multirow{8}{*}{ I I } & 1 & 1 & 0,70 & 0,42 & 0,19 & 0,13 & 0 \\
\hline & 2 & 1 & 0,54 & 0,40 & 0,18 & 0,10 & 0 \\
\hline & 3 & 1 & 0,65 & 0,45 & 0,17 & 0,09 & 0 \\
\hline & 4 & 1 & 0,54 & 0,39 & 0,17 & 0,10 & 0 \\
\hline & 5 & 1 & 0,51 & 0,43 & 0,18 & 0,09 & 0 \\
\hline & 6 & 1 & 0,52 & 0,32 & 0,14 & 0,05 & 0 \\
\hline & 7 & 1 & 0,63 & 0,52 & 0,21 & 0,12 & 0 \\
\hline & 8 & 1 & 0,80 & 0,61 & 0,27 & 0,15 & 0 \\
\hline \multirow{8}{*}{ I I I } & 1 & 1 & 0,75 & 0,53 & 0,21 & 0,11 & 0 \\
\hline & 2 & 1 & 0,77 & 0,56 & 0,25 & 0,14 & 0 \\
\hline & 3 & 1 & 0,73 & 0,59 & 0,27 & 0,12 & 0 \\
\hline & 4 & 1 & 0,79 & 0,62 & 0,24 & 0,10 & 0 \\
\hline & 5 & 1 & 0,87 & 0,57 & 0,21 & 0,11 & 0 \\
\hline & 6 & 1 & 0,84 & 0,56 & 0,27 & 0,16 & 0 \\
\hline & 7 & 1 & 0,75 & 0,55 & 0,24 & 0,15 & 0 \\
\hline & 8 & 1 & 0,64 & 0,50 & 0,22 & 0,12 & 0 \\
\hline \multirow{8}{*}{ IV } & 1 & 1 & 0,79 & 0,54 & 0,26 & 0,12 & 0 \\
\hline & 2 & 1 & 0,78 & 0,51 & 0,22 & 0,15 & 0 \\
\hline & 3 & 1 & 0,55 & 0,39 & 0,16 & 0,09 & 0 \\
\hline & 4 & 1 & 0,86 & 0,62 & 0,38 & 0,14 & 0 \\
\hline & 5 & 1 & 0,75 & 0,45 & 0,18 & 0,12 & 0 \\
\hline & 6 & 1 & 0,78 & 0,53 & 0,23 & 0,13 & 0 \\
\hline & 7 & 1 & 0,68 & 0,48 & 0,19 & 0,12 & 0 \\
\hline & 8 & 1 & 0,71 & 0,51 & 0,22 & 0,14 & 0 \\
\hline
\end{tabular}


Tabela 18 - Valores mēdios de umidade volumētria adimensionali zada $(\Omega)$ e fração de āgua liberada $(\lambda)$, para cada classe textural da camada $0-20 \mathrm{~cm}$.

\begin{tabular}{lcccccc}
\hline C1asse & $\Omega_{0,0025}$ & $\Omega_{0,03}$ & ${ }^{\Omega_{0}} 0,06$ & $\Omega_{0,33}$ & ${ }_{1} 1$ & ${ }^{\Omega} 15$ \\
\hline Muito Argiloso & 1 & 0,74 & 0,61 & $\mathbf{0 , 3 0}$ & 0,16 & 0 \\
Argiloso & 1 & 0,67 & 0,46 & 0,19 & 0,11 & 0 \\
Areno-Argiloso & 1 & 0,53 & 0,32 & 0,13 & 0,07 & 0 \\
Areno-Barrento & 1 & 0,32 & 0,16 & 0,10 & 0,06 & 0 \\
\hline
\end{tabular}

\begin{tabular}{lcccccc}
\hline C1asse & $\lambda_{0,0025}$ & $\lambda_{0,03}$ & $\lambda_{0,06}$ & $\lambda_{0,33}$ & $\lambda_{1}$ & $\lambda_{15}$ \\
\hline Muito Argiloso & 0 & 0,26 & 0,39 & 0,70 & 0,84 & 1 \\
Argiloso & 0 & 0,33 & 0,54 & 0,81 & 0,89 & 1 \\
Areno-Argiloso & 0 & 0,47 & 0,68 & 0,87 & 0,93 & 1 \\
Areno-Barrento & 0 & 0,68 & 0,84 & 0,90 & 0,94 & 1 \\
\hline
\end{tabular}




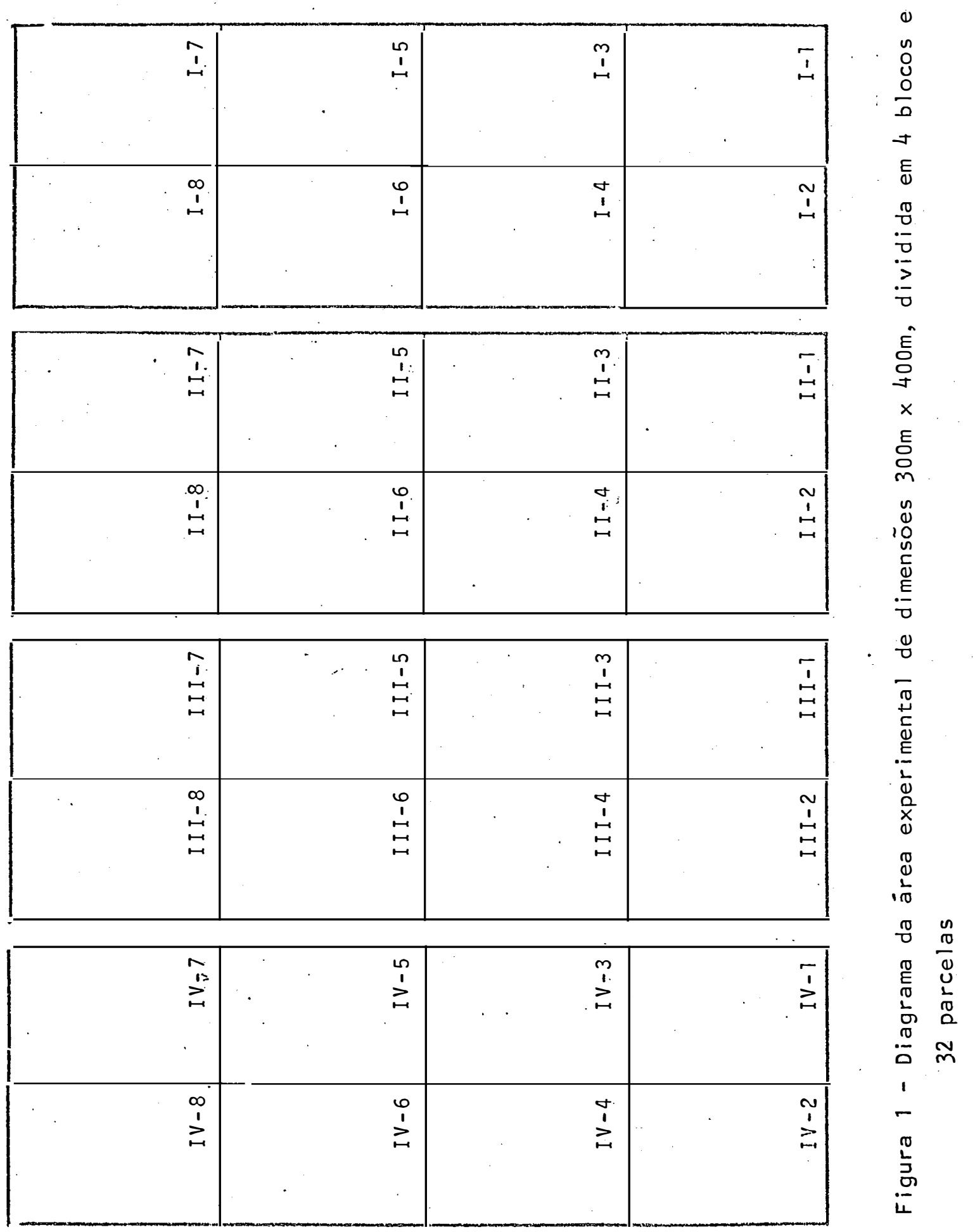




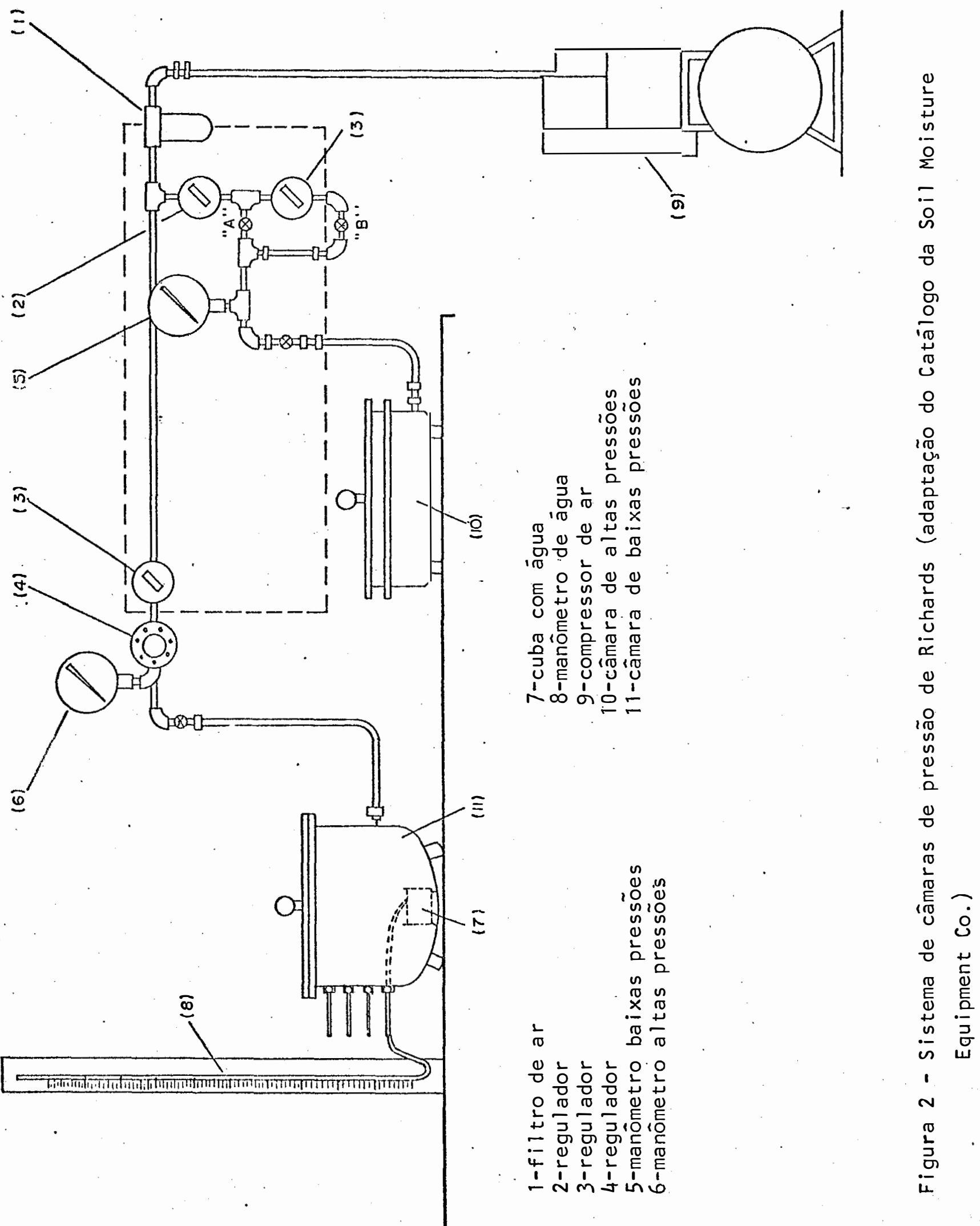




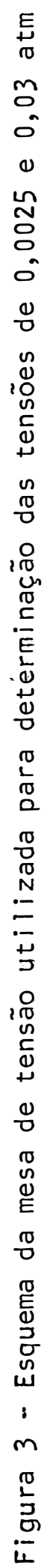

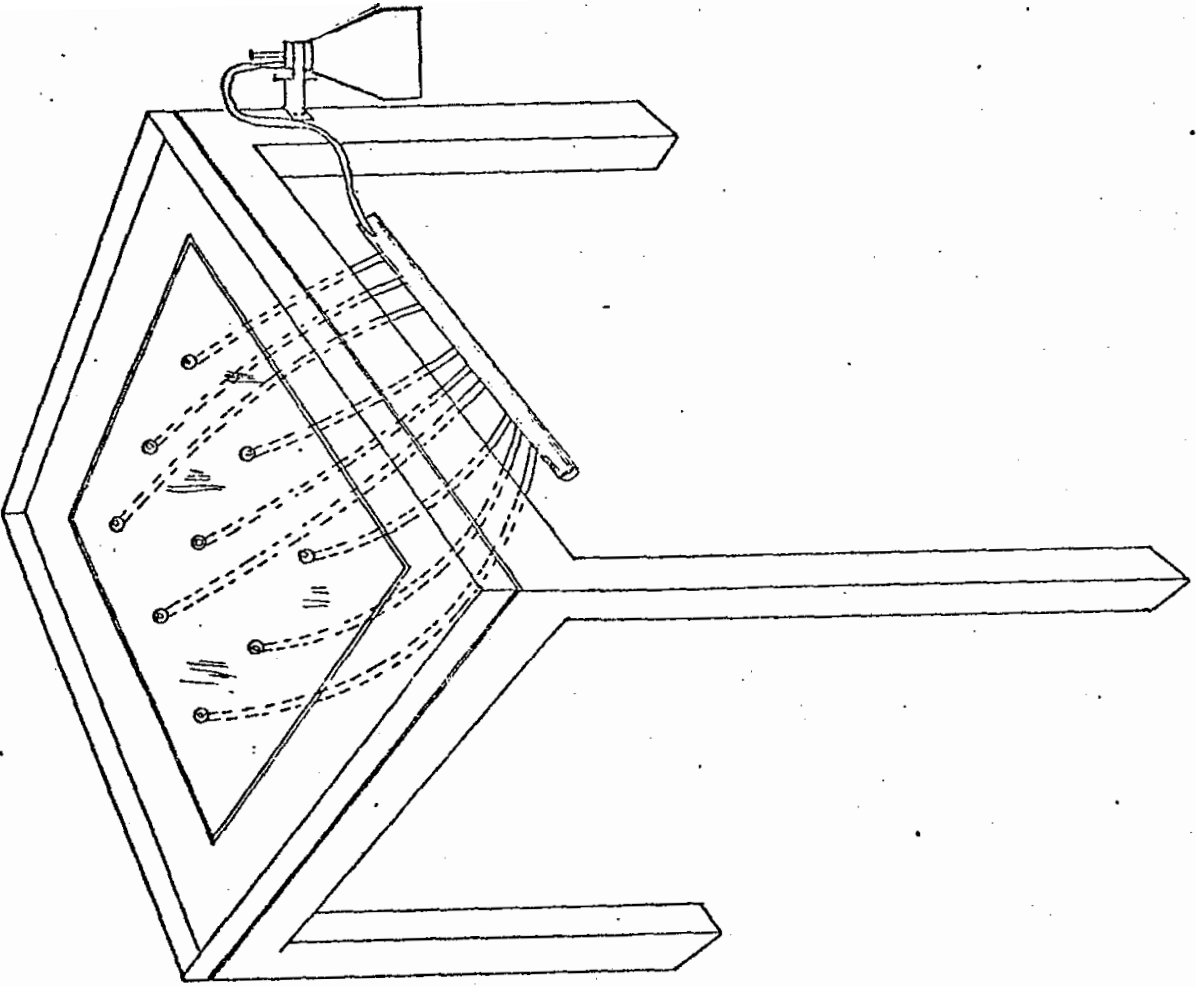




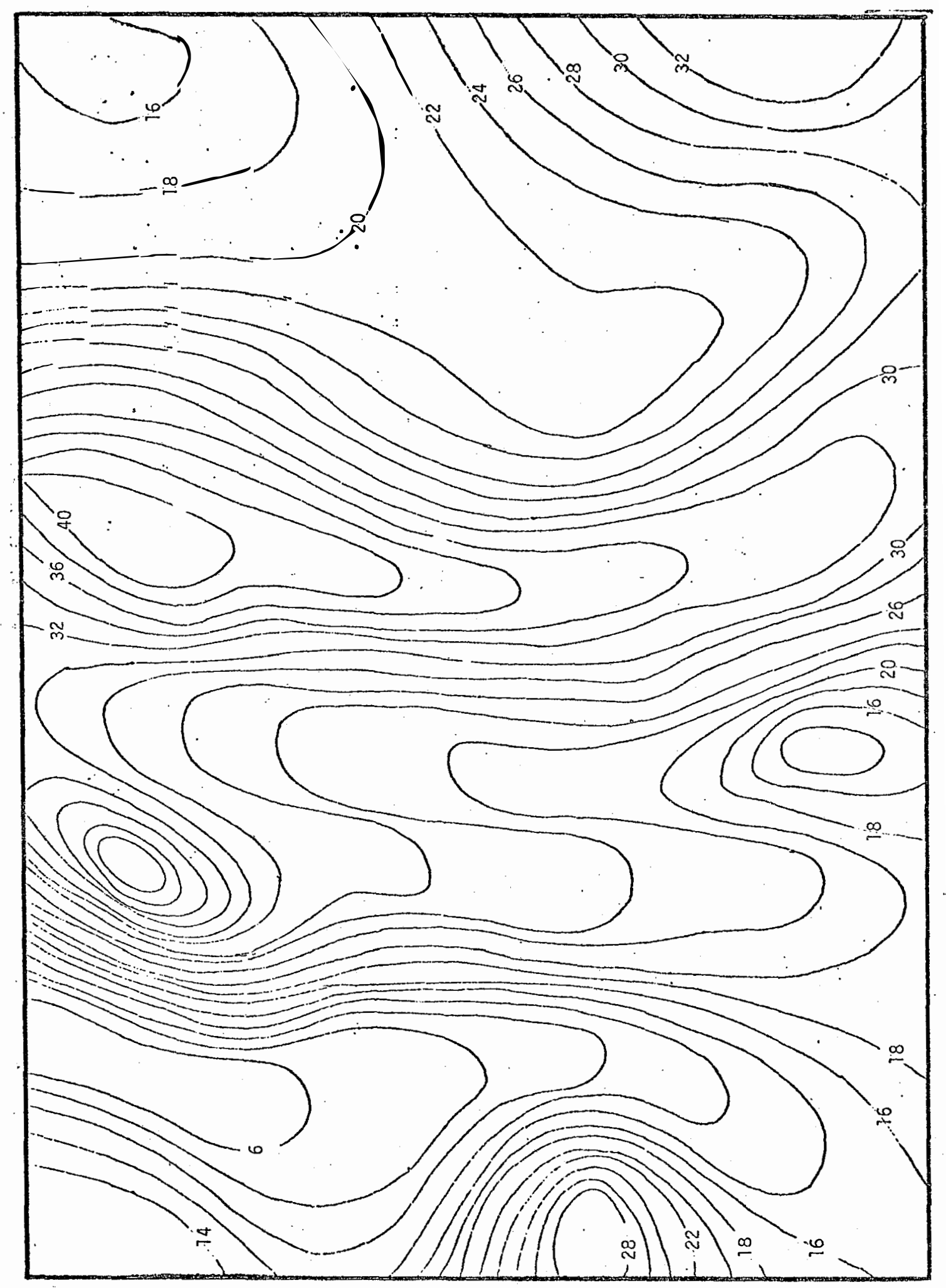

\begin{tabular}{l} 
U \\
0 \\
\multirow{1}{*}{}
\end{tabular} 


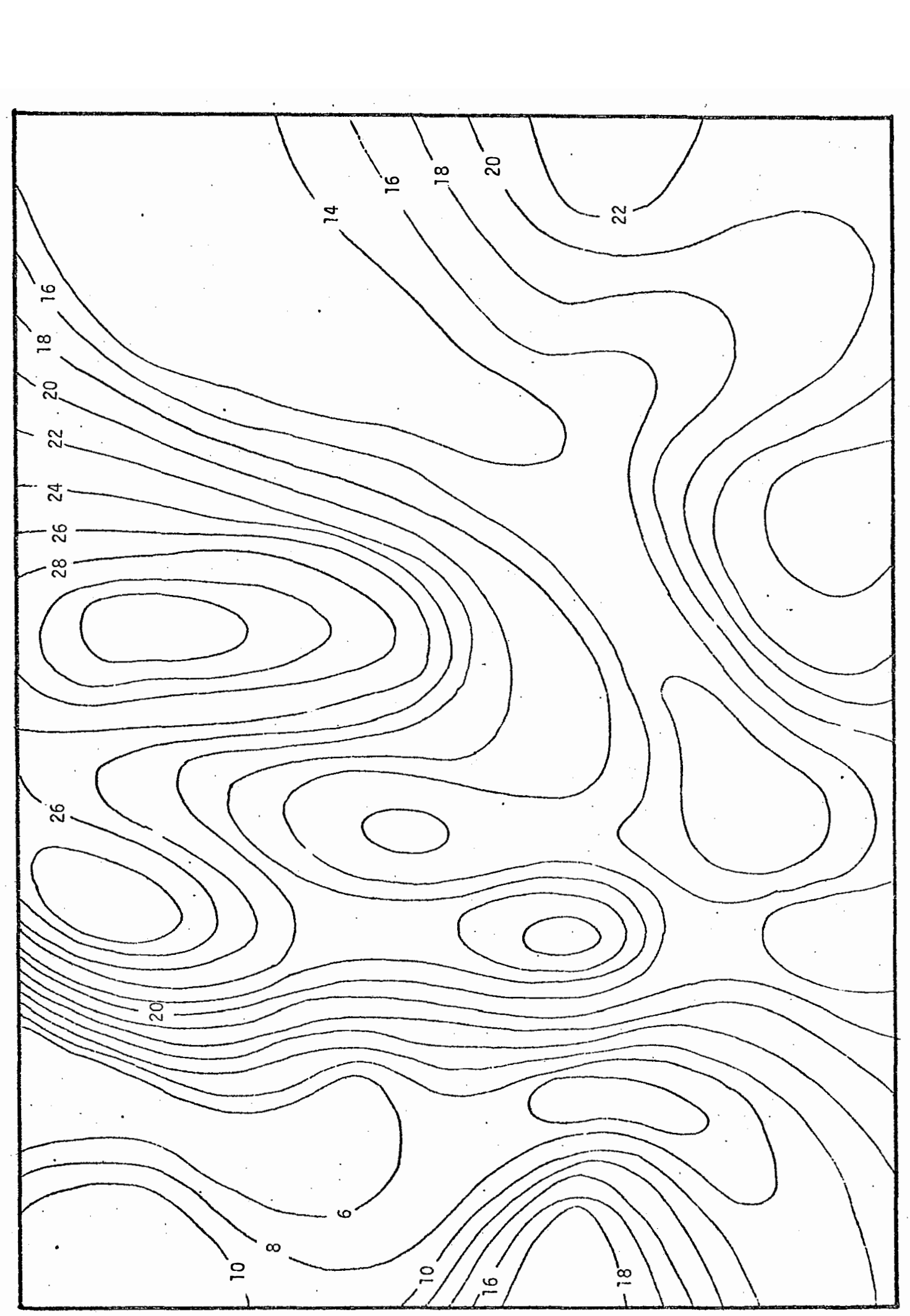

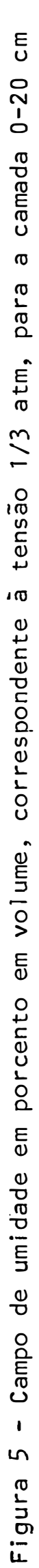




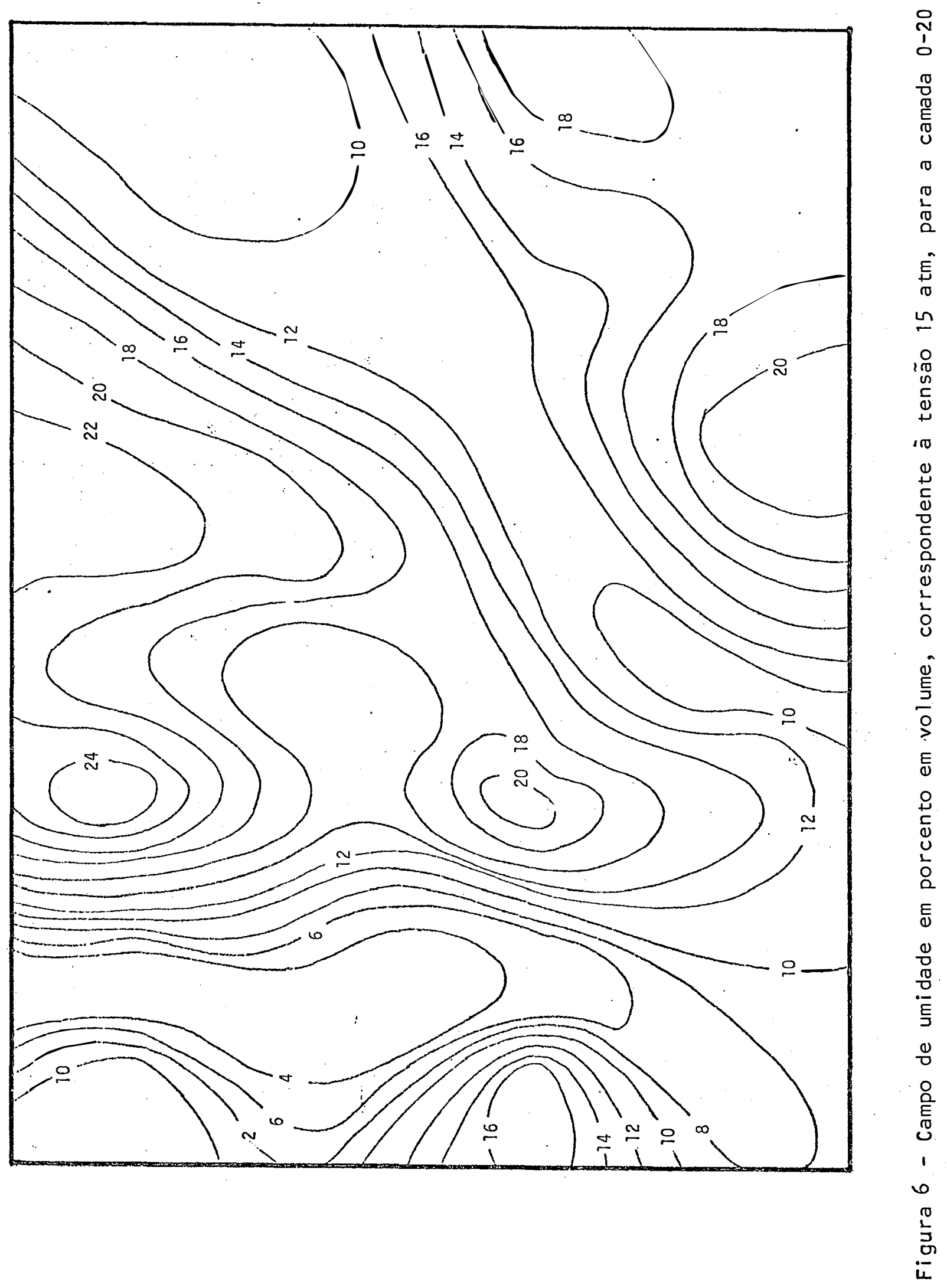




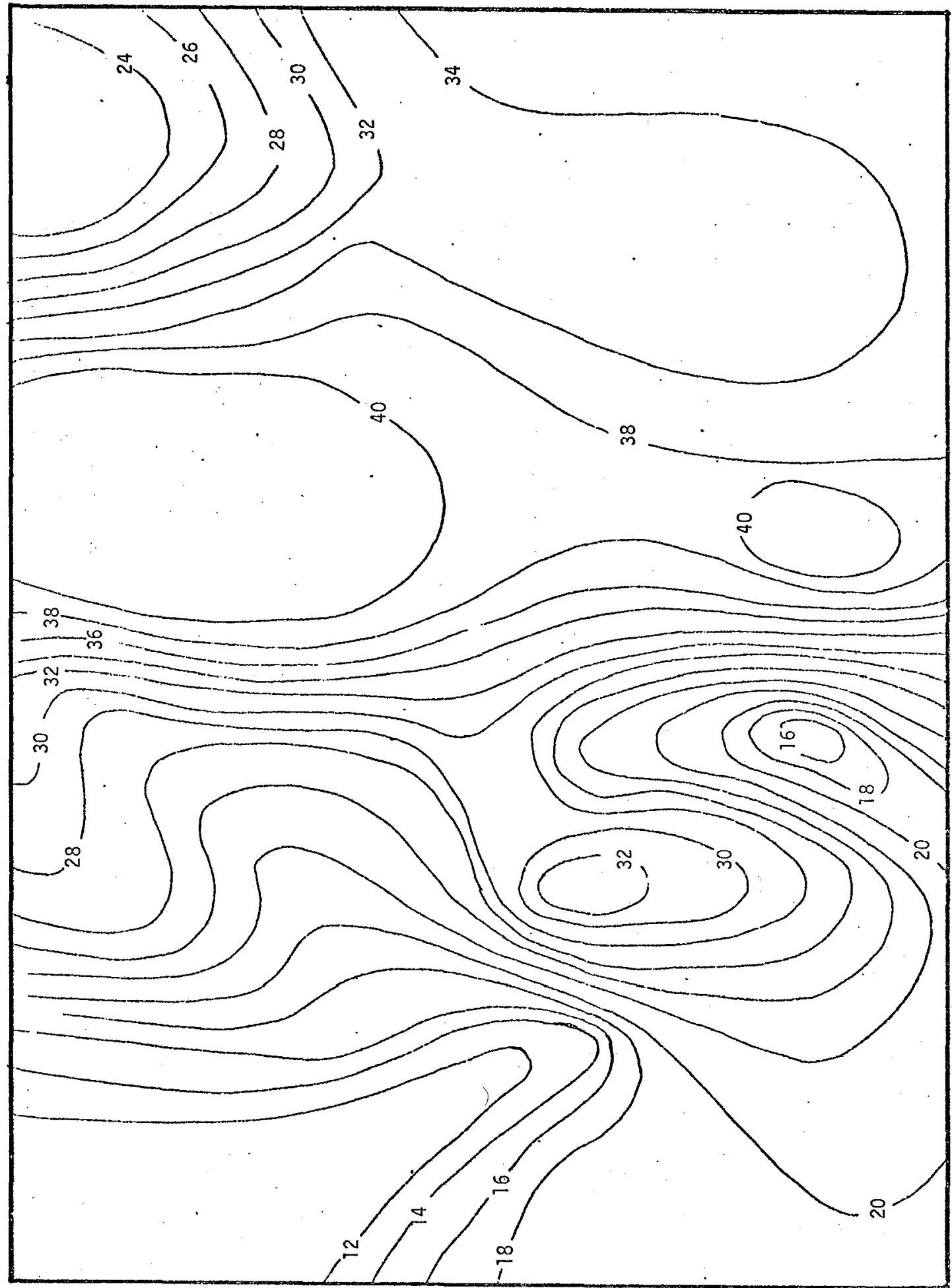

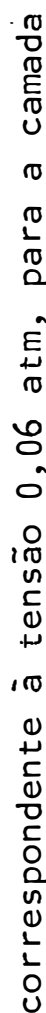

O 


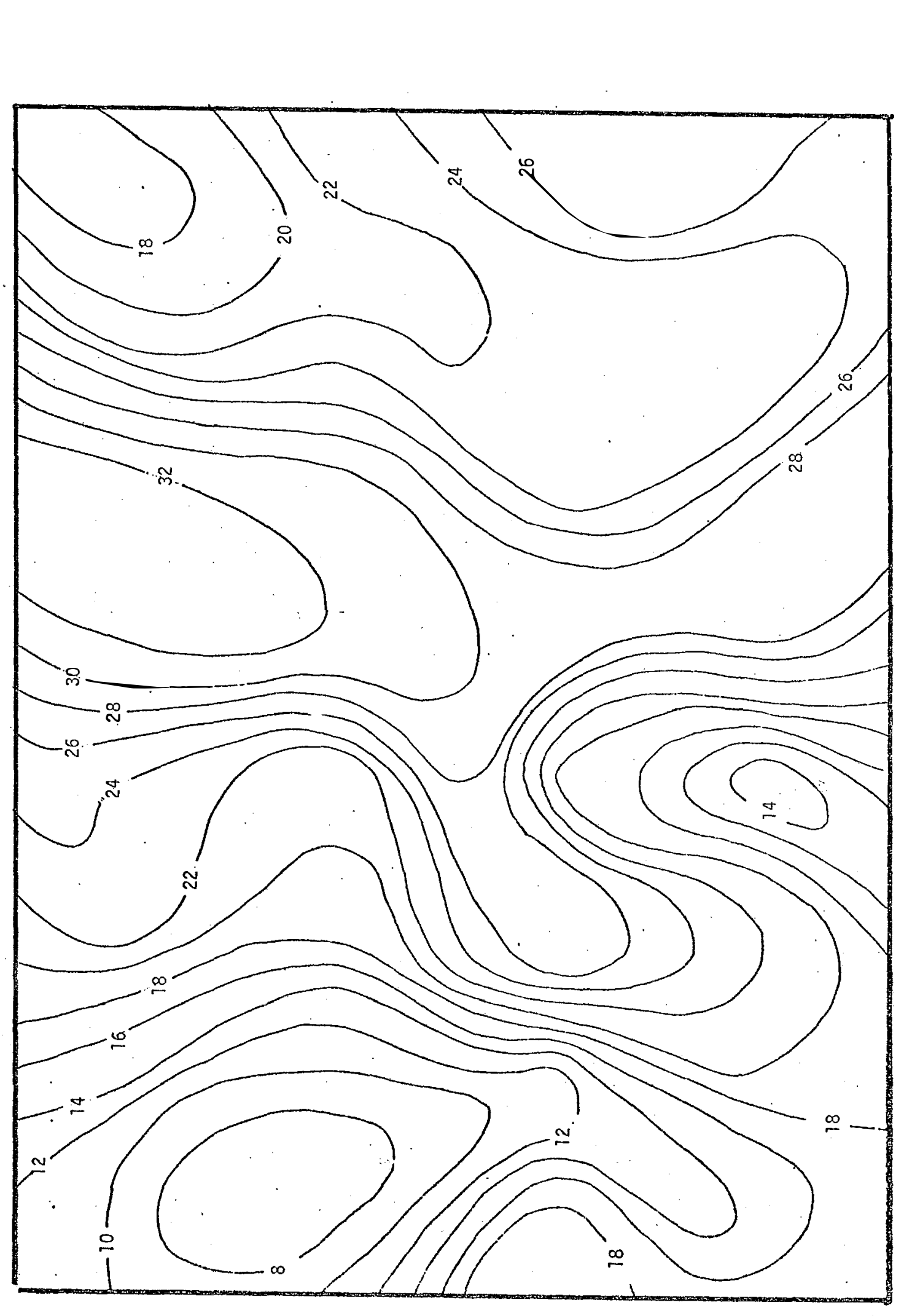

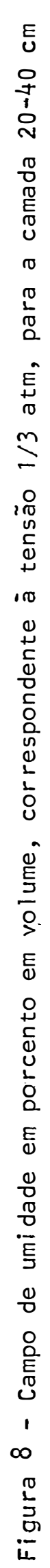




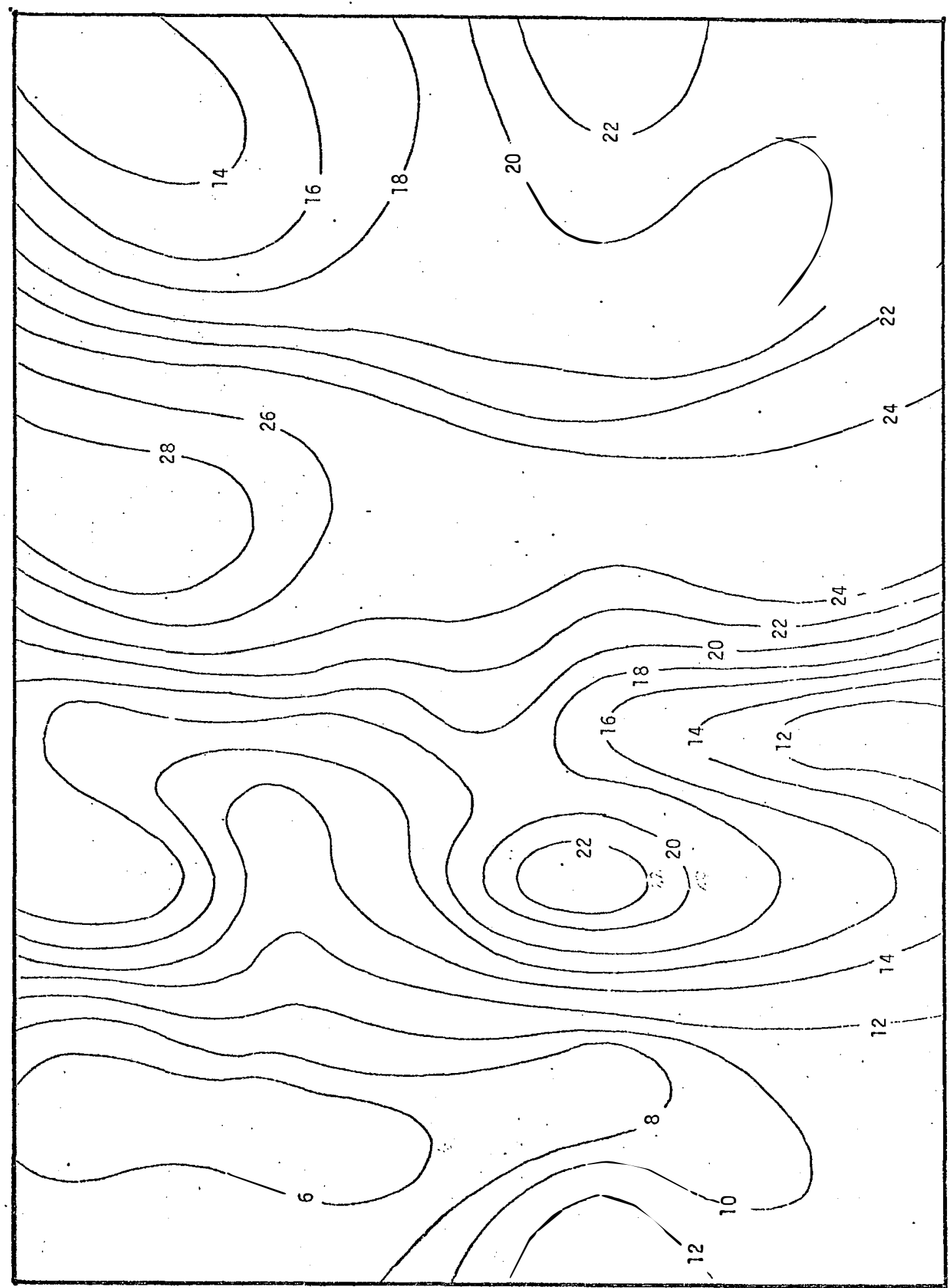

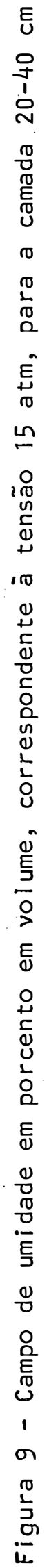






$\begin{array}{ll}E & \\ 0 & -60- \\ 0 & \\ 1 & \\ 0 & \end{array}$ 


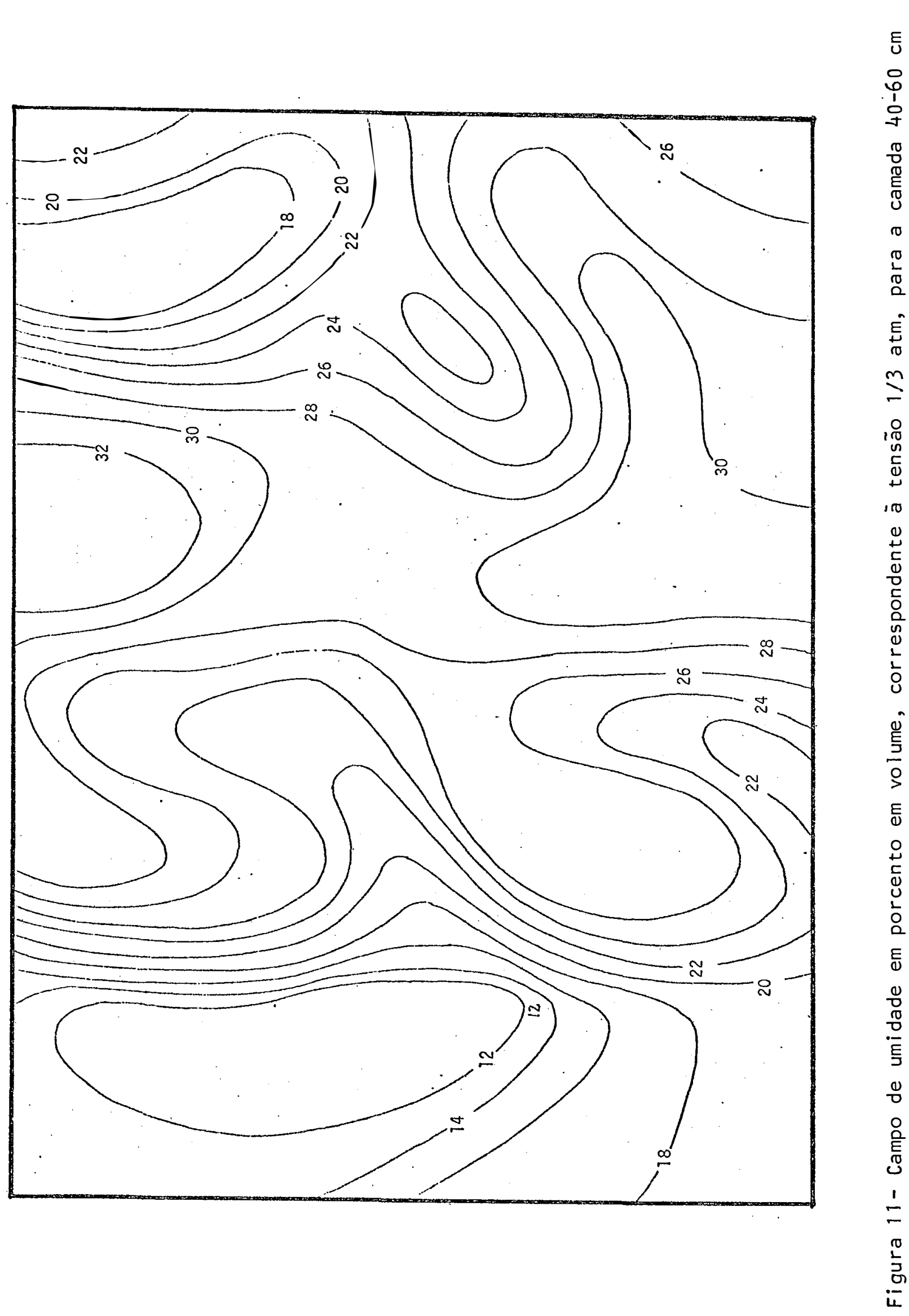




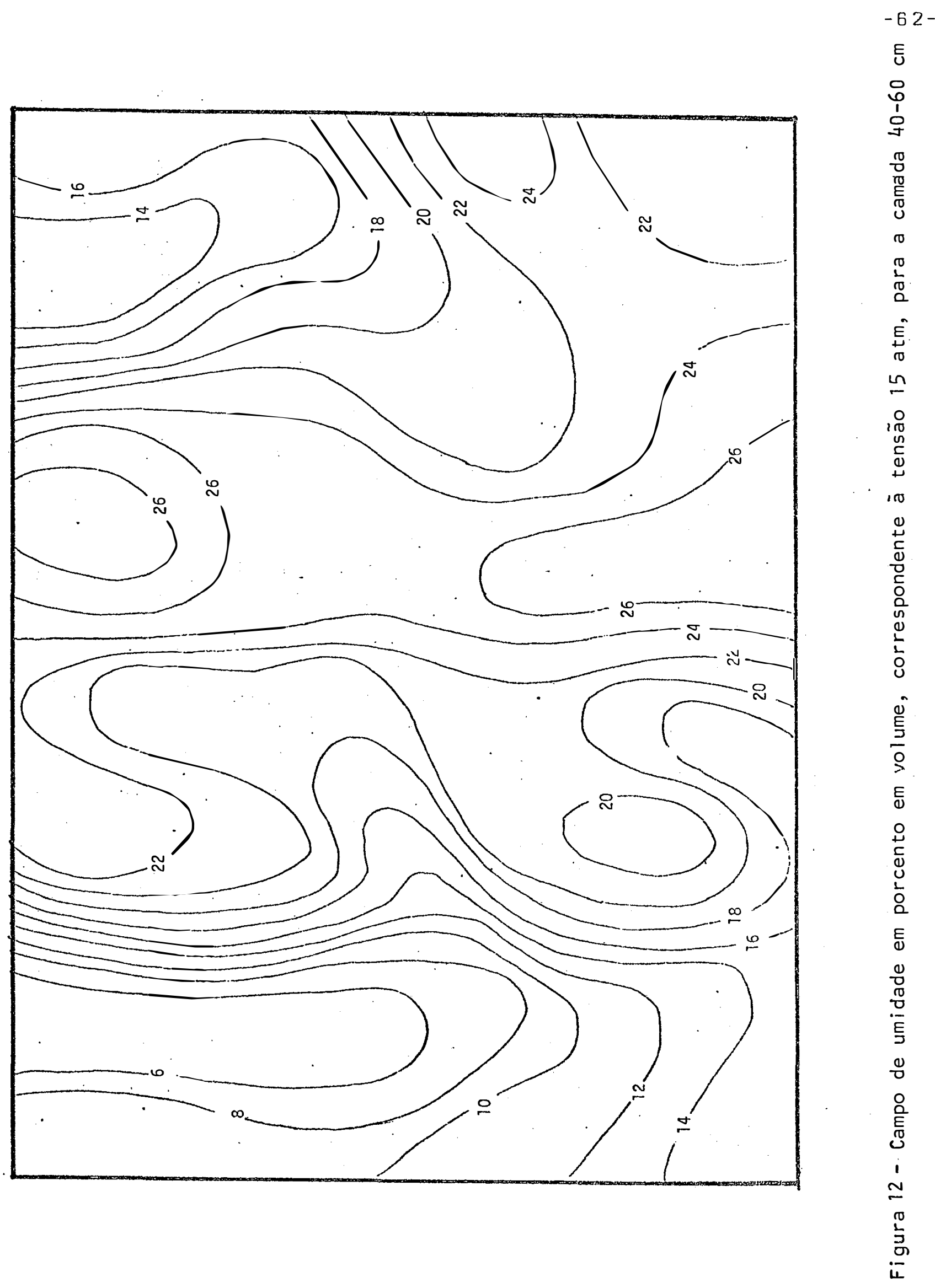




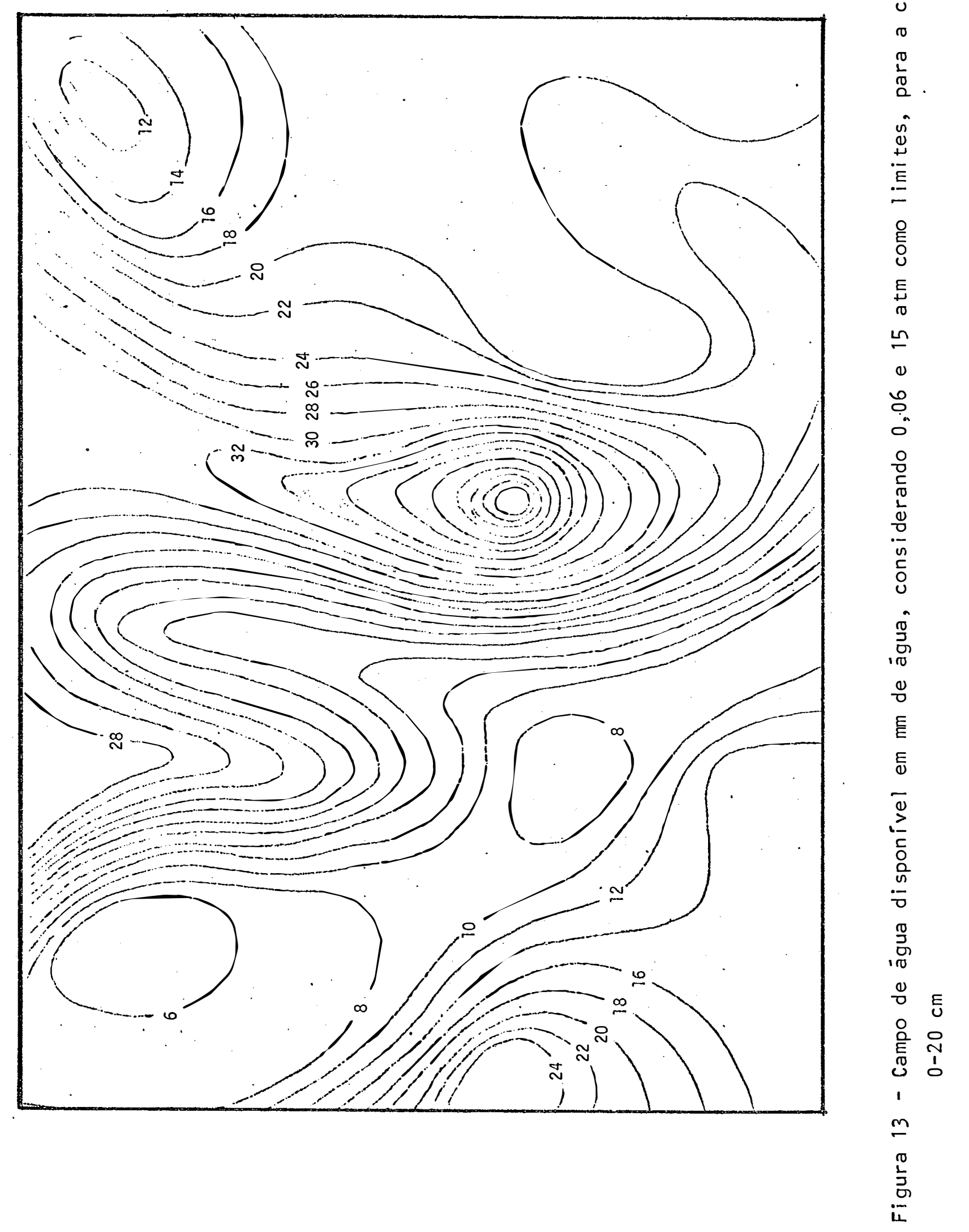




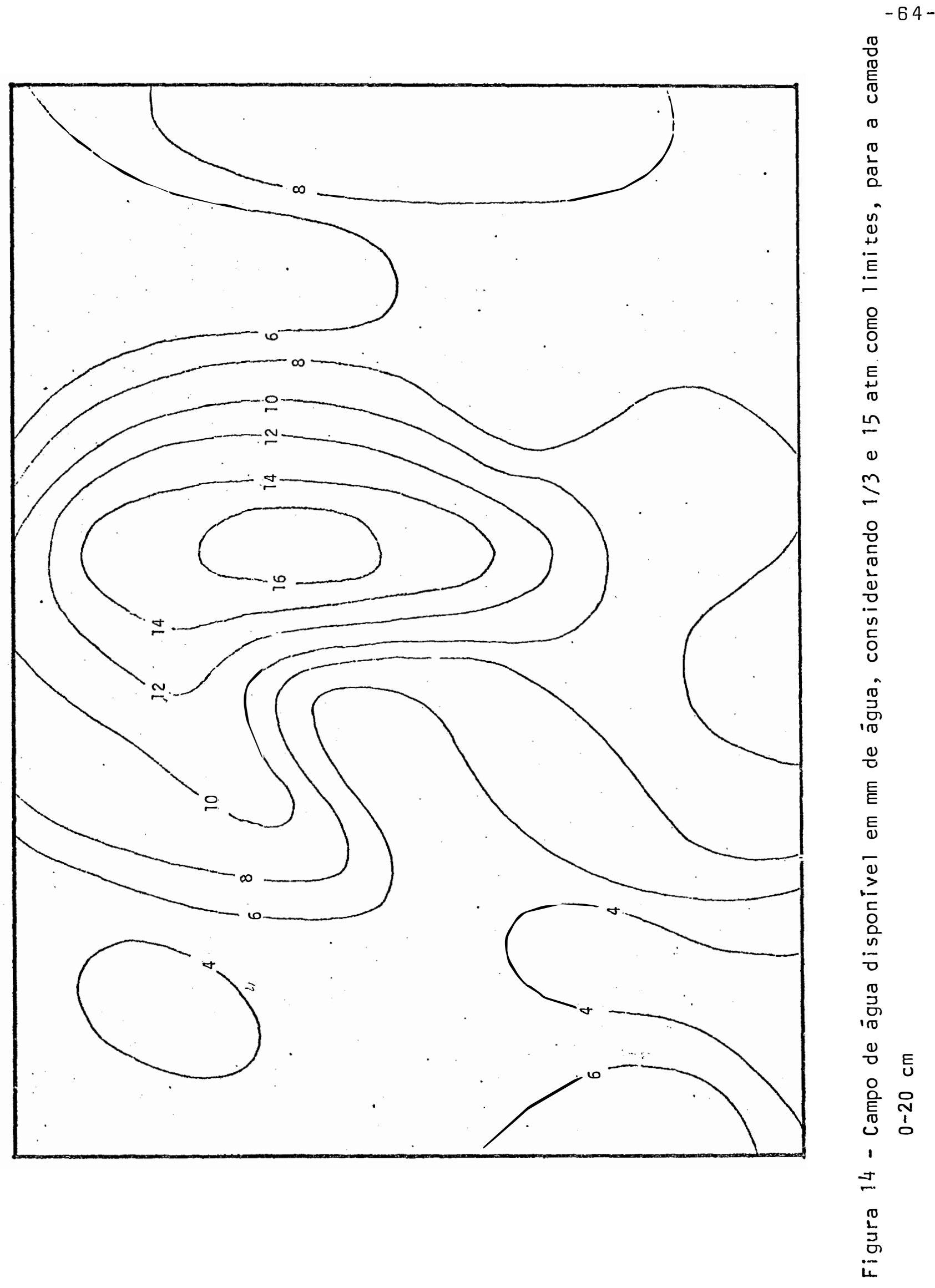




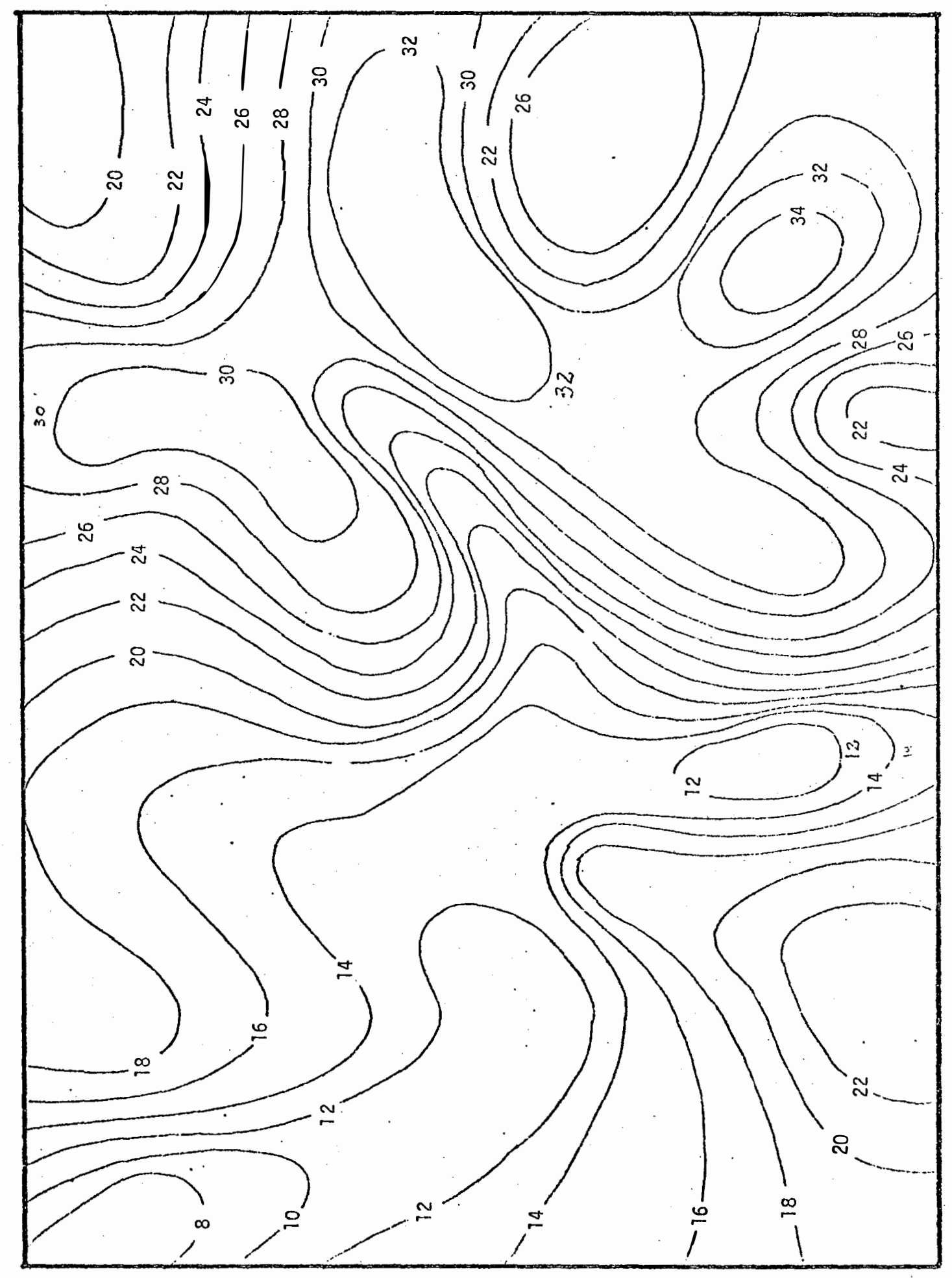

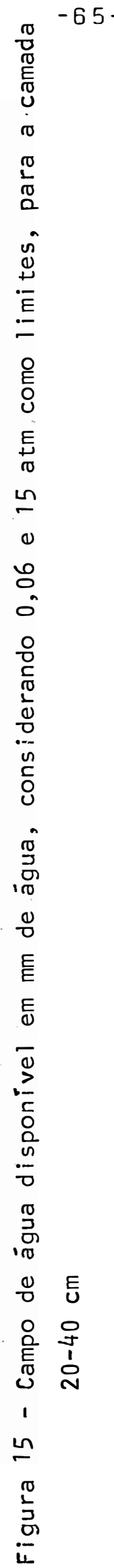




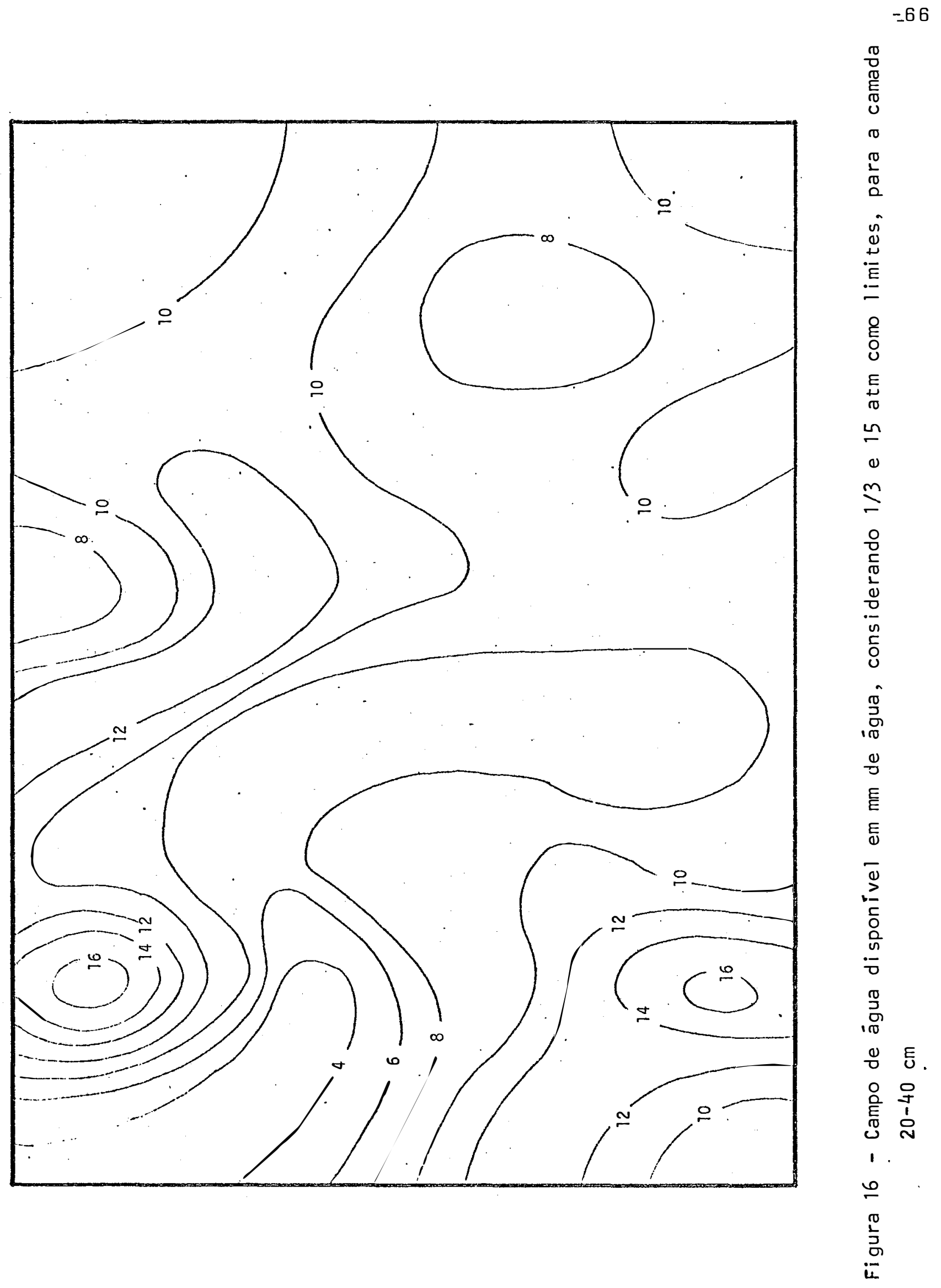




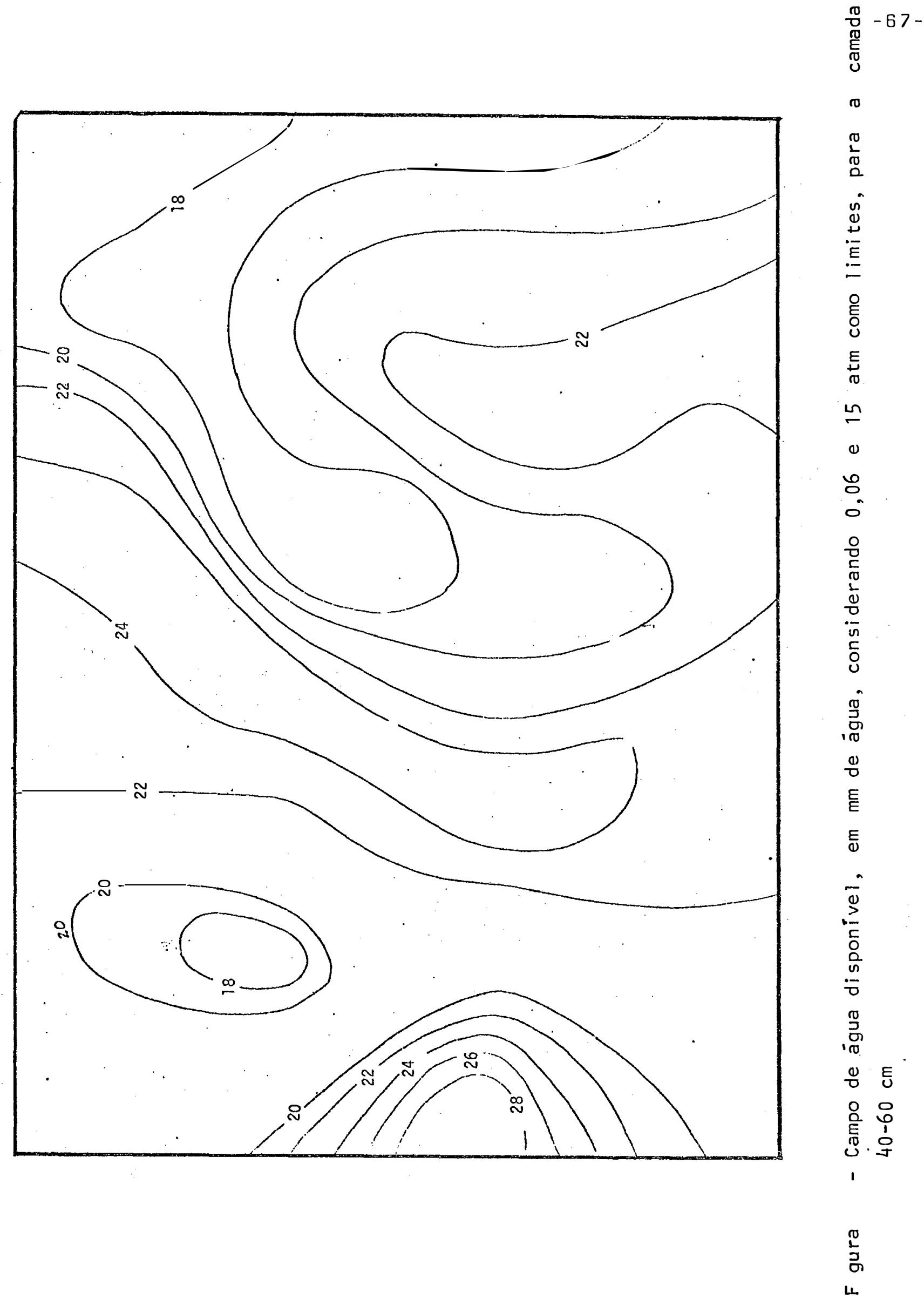




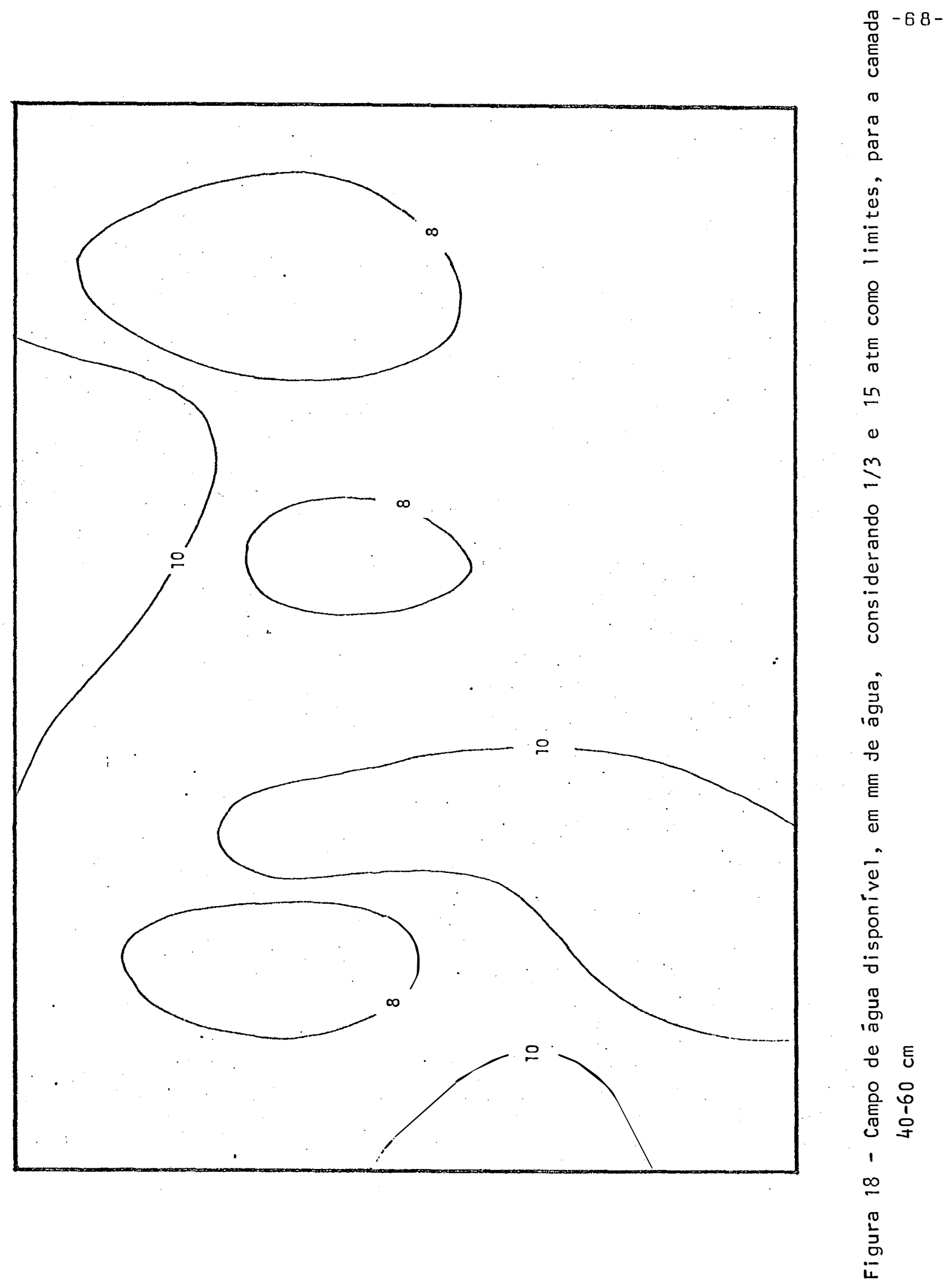




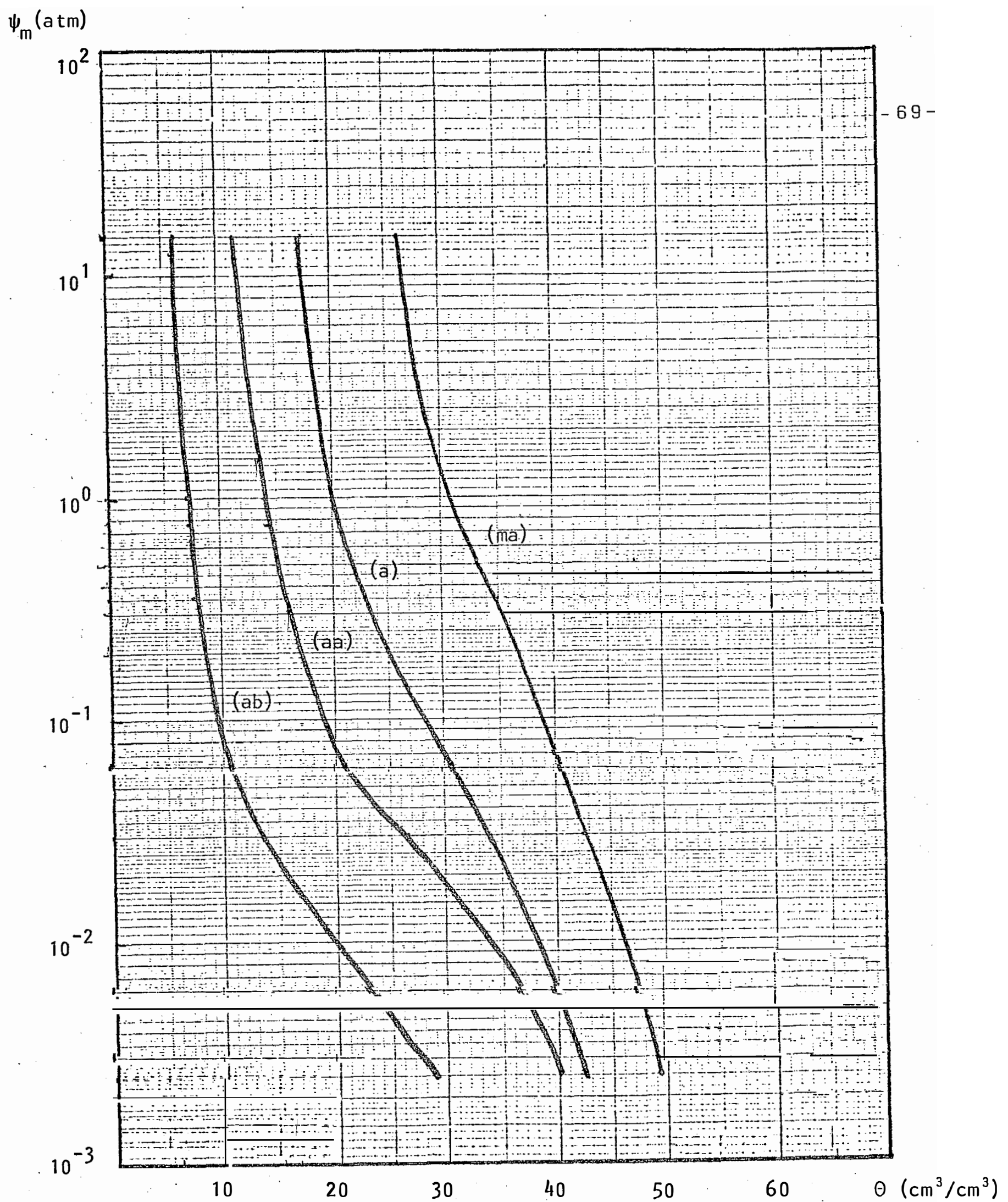

Figura 19 - Curvas características médias de retenção de ăgua, correspondente às classes texturais: muito argilosa (ma), argilosa (a), areno argilosa (aa) e areno-barrento (ab), da camada 0-20 cm de profundidade. 


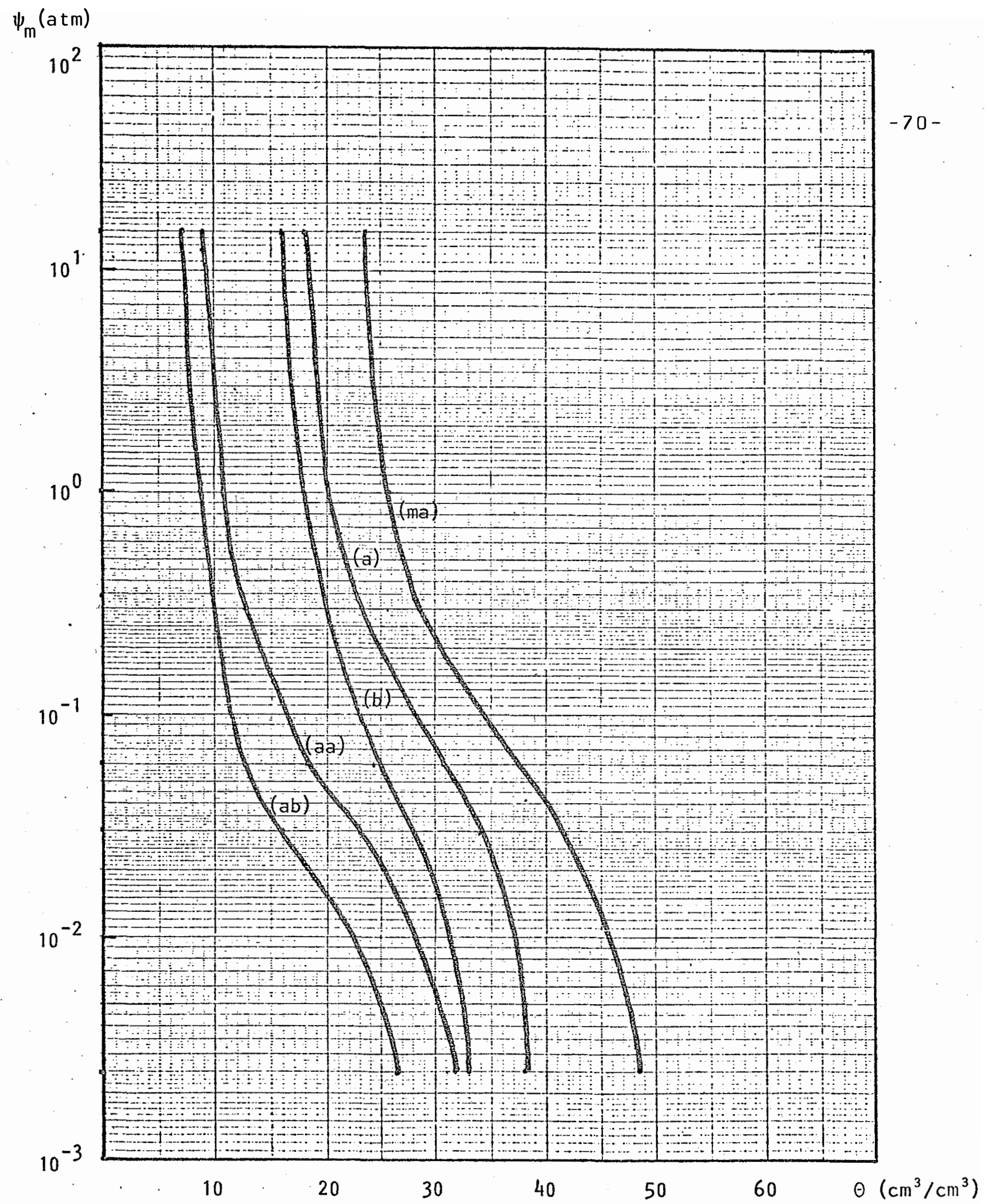

Figura 20 - Curvas características médias de retenção de ägua, correspondente às classes texturais: muito argilosa (ma), argilosa (a), barrento (b), areno-argilosa (aa) e areno-barrento (ab), da camada $20-40$ cm de profundidade. 
$\psi(\mathrm{atm})$

m

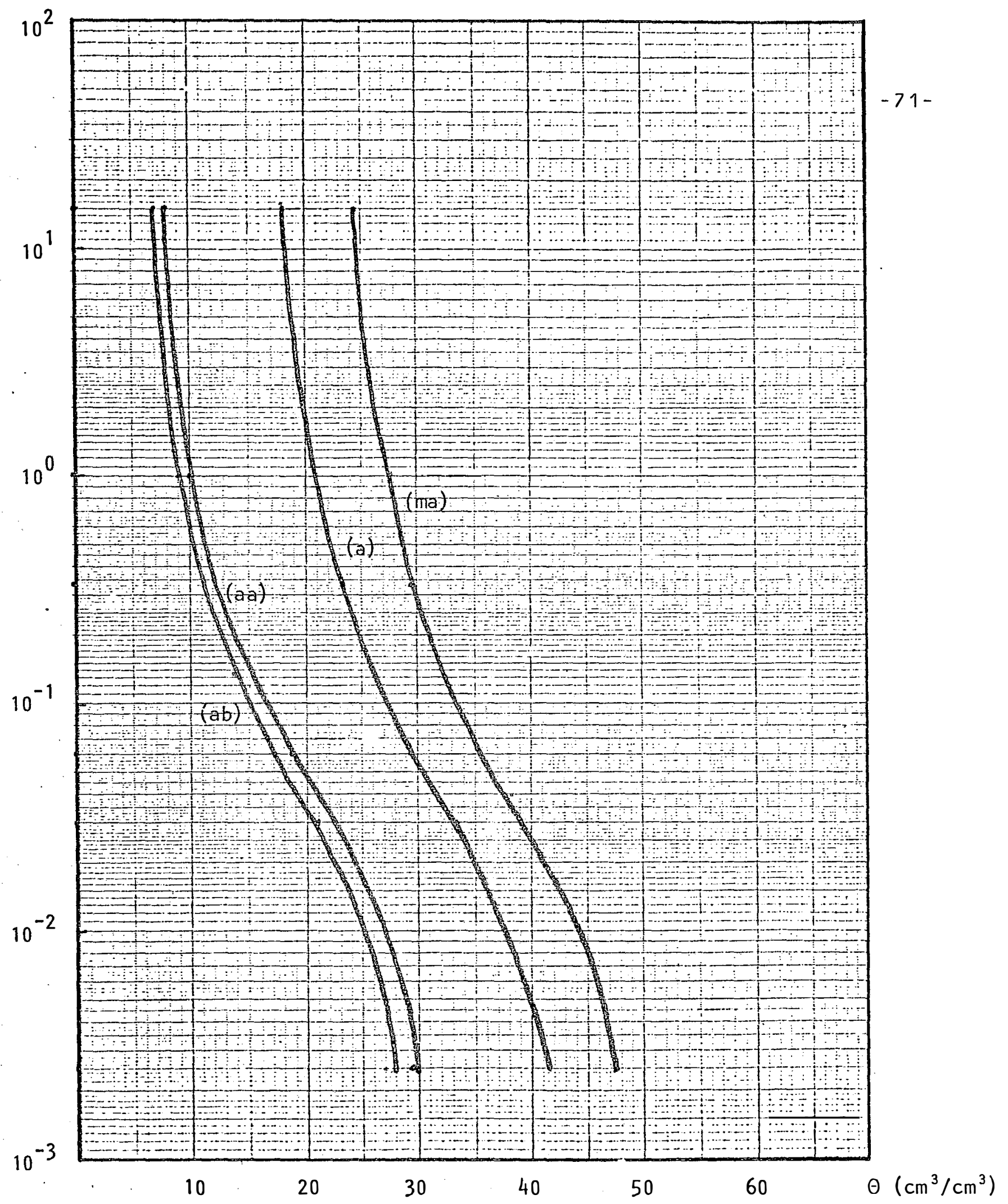

Figura 21 - Curvas características médias de retenção de ăgua correspondente às classes texturais: muito argilosa (ma), argilosa (a), areno-argilosa (aa) e areno-barrento (ab), da camada 40-60 cm de profundidade. 


\section{LITERATURA CITADA}

ABROL, I.P. e J.P. PALTA, 1968. Bulk density determination of soil clods using rubber solution as a coating material. Soil Science, New Brunswick, 106: 465-46.8.

ANDERSON, A.B., 1978. Aspectos florísticos e fitogeográficos de campinas e compinaranas na Amazónia Central. Manaus, INPA/FUA. 104p. (Tese de Mestrado).

BLACK, C.A.; D.D. EVANS; J.L. WHITE; L.E. ENSMINGER e F.E. CLARK, 1965. Methods of soil analysis: physical and mineralogical properties, including statistics of measurement and sampling. Madison, American Society of Agronomy. v. 1 (Agronomy, 9).

BRASHER, B.R.; D.P. FRANZMEIER; V. VALASSIS e S.E. DAVIDSON, 1966. Use of Saran resin to coat natural soil clods for

- bulk density and moisture reterition measurements. Soil Science, New Brunswick, 101(2): 108 . 
COLMAN, E.A., 1947. A laboratory procedure for determining of field capacity of soils. Soil Science, New Brunswick, $67: \quad 277-283$

E.U.A., 1975. Soil survey staff soil taxonomy - a basic system of soil classification for making and interpreting soil surveys. Washington, D.C., (Agriculture Handbook, 436, U.S. Government Printing Office).

FRANZMEIER, D.P.; E.P. WHITESIDE e A.E. ERICKSON, 1960.

- Relationship of texture classes of fine earth to readly available. Transactions of 7 th International Congress of Soil Science, Madison, 1: 354-363.

GARDNER, W.R., 1965. Dynamic aspects of soil water availability to plants. Annual Review of Plant Physiology, Palo Alto, $16: 323-342$.

GROHMANN, F., 1960. Distribuição e tamanho dè poros em três tipos de solo do Estado de São Paulo. Bragantia, Campinas, $19: \quad 319-328$.

GROHMANN, F. e H.P. MEDINA, 1962. Características de umidade dos principais solos do Estado de São Paulo. Bragantia, Campinas, 21(8): 285-293.

JAMISON, V.C. e'I.F. REED, 1949. Durable asbestos tension table. Soil Science, New Brunswick, 67: 311-318. 
JAMISON, V.C.; H.H. WEAVER e I.F. REED, 1950. A hammer-driven soil core sampler. Soil Science, New Brunswick, 69:487-496.

JAMISON, V.C., 1956. Pertinent factors governing the availability of soil moisture to plants. Soil Science, New Brunswick, $\dot{8} 1: 459-471$.

JAMISON, V.C. e E.M. KROTH, 1958. Available moisture storage* capacity in relation to textural composition and organic matter content of several Missouri soils. Proceedings Soil Science Society of America, Madison, 22: 189-192.

KIEHL, E.J., 1979. Manual de edafologia; - relações solo-planta. São Paulo, Editora Agronómica Ceres. $264 \mathrm{p}$.

LUTZ, J.F., 1947. Apparatus for collecting undisturbed soil samples. Soil Science, New Erunswick, 64: 399-401.

MACLEAN, A.H. e T.U. YAGER, 1972. Available water of Zambian $x$ soils in relation to pressure plates measurements and particle size análysis. Soil Science, New Brunswick, 113: 23-29.

MARSHALL, T.J., 1959. Distribution of water in soil.. In: Comm. Bur. Soils Tech. Commun., eds. Relation between water and soiz. p. 39-45.

NYE, P.H. e O.J. GREENLAND, 1960. The soil under the shifting 
cultivation. Comm. Bur. of Soils, Harpendn, England.

PETERSEN, G.W.; R.L. CUNNINGHAM e R.P. MATELSKI, 1968. Moisture characteristics of Pennsylvania soils: I. Moisture retention related to texture. Proceedings Soil Science Society of America, Madison, 32(2): 271-275.

PREVEdelLo, C.L., 1978. Fluxo bidimensional de água à raiz da planta. Santa Maria, UFSM/RS. 64p. (Dissertação de Mestrado).

RANZANI, G., 1980. Identificação e caracterização de alguns solos da Estação Experimental de Silvicultura Tropical do INPA. Acto Amazonica, Manaus, 10(1): 7-41.

REICHARDT, K., 1975. Processos de transferência no sistema solo-planta-atmosfera. Piracicaba, Fundação Cargill. 286 .

RICHARDS, L.A. e M. FIREMAN, 1943. Pressure plate apparatus * for measuring moisture sorption and transmission by soils. Soil Science, New Brunswick, 56: 395-404.

RICHARDS, L.A. e L.R. WEAVER, 1943. Fifteen atmosphere percentage as related to the permanent wilting percentage. Soil Science, New Brunswick, 56: 331-339.

RICHARDS, L.A:, 1949. Methods of measuring soil moisture tension. Soil Science, New Brunswick, 68: 95-112. 
RICHARDS, L.A. e C.H. WADLEIGH, 1952. Soil water and plant growth. In: Soil physical conditions and plant growth. p. 13. Am. Soc. Agron. Monograph. 2. Fundação Cargill. $285 p$.

RIVER, E.D. e R:F. SHIPP, 1978. : Soil water retention as related to particle size in selected sands and Loamy sands. Soil Science, New Brunswick, 126: 94-100.

ROBERTSON, L.S. e H. KOHNKE, 1946. The pF at the wilting point of several Indiana soils. Proceedings Soil Science Society of America, Madison, 11: 50-52.

SALTER, P.J. e F. HAWORTH, 1961. The available water capacity of a sandy loam soil. I. A critical comparison of methods of determining the moisture content of soil at field capacity and the permanent wilting point. Journal of Soit Science, 0xford, 12 : 326-334.

SALTER, P.J. e J.B. WILLIAMS, 1965a. The influence of texture on the moisture characteristics of soils. I. A critical comparison of technique for determining the available water capacity and moisture characteristic curve of a soil. Journal of Soil Science, oxford, 16: 1-15.

SALTER, P,J. é J.B. WILLIAMS, 1965b. The influence of texture on the moisture characteristics of soils. II. Available 
water capacity and moisture release characteristics. Journal of Soil Science, Oxford, 16: 310-317.

SALTER, P.J.; G. BERRY e J.B. WILLIAMS, 1966. The influence of texture on the moisture characteristics of soils. III. Quantitative relationship between particle size composition and available water capacity. Journal of Soiz Science, 0xford, 17: 93-98.

SALTER, P.J. e J.B. WILLIAMS, 1969. The influence of texture on moisture characteristics of soil. Journal of Soil Science, oxford, 20: 126-131.

SLAVICK, B., 1974. Water exchange between plant roots and soil. Apud PREVEdelLo, C.L., 1978.

SMITH, R.M. e D.R. BROWNING, 1947. Soil moisture tension and pore space relations for several soils in the rang of "field capacity". Proceedings Soil Science Society of America, Madison, 12: 17-21.

SOIL SURVEY STAFF, 1960. Soil classification. 7th. Approx. and Suppl. U.S. Dept. Agr., Washington. Soil Science, $133: 29$.

TAYLOR, S.A. (s.d.). Evaluating soil water. Bulz. Utah Agric: Experim. Station, Utah State University, Logan, $n ! 426$. 
TISDALL, A.L., 1951. Comparison of methods of determining apparent density of soils. Australian Journal Agricultural Research, Melbourne, 2: 349-354.

VAN BAVEL, C.H.M.; N. UNDERWDOD e S.R. RAGAR, 1957. Transmission of gamma radiation by soils and soil densitometry. Proceedings Soil Science Society of America, Madison, 21: $588-591$.

VEIHMEYER, F.J. e A.H. HENDRICKSON, 1927. Soil moisture condition in relation to plant growth. Plant Physiology, Lancaster, 2: 71 .

VEIHMEYER, F.J. e A.H. HENDRICKSON, 193i. The moisture equivalent as a measure of the field capacity of soils. 'Soil Science, New Brunswick, 32 : 181-193.

VEIHMEYER, F.J. e A.H. HENDRICKSON, 1949, Methods of measuring field capacity and permanerit wilting percentage of soils. Soil Science, New Brunswick, 68: 75-95.

VOMOCIL, J.A., 1965. Porosity. In: BLACK, C.A., ed. Methods in soiz analysis. Madison, American Society of Agronomy. v. 1. (Agronomy, 9). 